\title{
Zic1 and Zic3 Regulate Medial Forebrain Development through Expansion of Neuronal Progenitors
}

\author{
Takashi Inoue, ${ }^{1}$ Maya Ota, ${ }^{1}$ Miyuki Ogawa, ${ }^{1}$ Katsuhiko Mikoshiba, ${ }^{2}$ and Jun Aruga ${ }^{1}$ \\ ${ }^{1}$ Laboratory for Comparative Neurogenesis, and ${ }^{2}$ Laboratory for Developmental Neurobiology, RIKEN Brain Science Institute, Wako-shi, Saitama 351-0198, \\ Japan
}

The medial telencephalon is a source of neurons that follow distinct tangential trajectories of migration to various structures such as the cerebral cortex, striatum, and olfactory bulb. In the present study, we characterized the forebrain anomalies in Zicl/Zic3 compound mutant mice. Zicl and Zic3 were strongly expressed in the medial structures, including the septum, medial cerebral cortex, and choroid plexus. Mice homozygous for the Zic1 mutant allele together with the null Zic3 allele showed medial forebrain defects, which were not obvious in either Zic1 or Zic3 single mutants. Absence of both Zic1 and Zic3 caused hypoplasia of the hippocampus, septum, and olfactory bulb. Analysis of the cell cycle revealed that the cell cycle exit rate was increased in the septa of double mutants. Misexpression of Zic3 in the ventricular layer of the cerebral cortex inhibited neuronal differentiation. These results indicated that both Zicl and Zic3 function in maintaining neural precursor cells in an undifferentiated state. The functions of these genes may be essential to increasing neural cell numbers regionally in the medial telencephalon and to proper mediolateral patterning of the telencephalon.

Key words: forebrain development; neuronal progenitors; neuronal differentiation; olfactory bulb; septum; Zic

\section{Introduction}

During development, the mammalian forebrain acquires a large number of cells that are essential for higher function. Multipotent neural progenitors are first maintained in a proliferative state to ensure that the correct number of cells will be generated. The extent of cell proliferation may be specifically defined by the developmental stage and by regional identities in the neuroepithelium (Rubenstein et al., 1998; Marin and Rubenstein, 2001). Transition from precursor cell proliferation to neural differentiation requires the coordinated action of several basic helix-loophelix (HLH) and homeobox transcription factors (TFs), which directly or indirectly act on cell cycle regulatory molecules to instruct the cells to leave their mitotic state and, thus, promote differentiation (Guillemot, 2005). However, HLH and homeodomain TFs may not be sufficient for the proper regulation of differentiation, as indicated by the occurrence of several TF mutant mice lines that show telencephalic phenotypes (Zaki et al., 2003).

Zic2 is one such TF. Mice homozygous for the Zic2 hypomorphic allele (Zic2 $k d / k d$ ) show holoprosencephaly (HPE), in which the medial part of the forebrain is defective (Nagai et al., 2000). The forebrain phenotype is analogous to those found in HPE

Received Sept. 15, 2006; revised March 23, 2007; accepted April 11, 2007.

This work was supported by RIKEN Brain Science Institute Funds and by a Grant-in-Aid for Scientific Research from the Ministry of Education, Culture, Sports, Science, and Technology of Japan. We thank Masaharu Ogawa, Yoshinobu Sugitani for valuable discussions, Yoshihiro Yoshihara for Tbx21 antibody and critical comments on this manuscript Toshiaki Okada and Kei-ichi Katayama for technical advice on the electroporation experiment, Andy McMahon and Shinji Takada for the Wnt3a probe, Jun-ichi Miyazaki for the pCAG-GS plasmid, and Research Resource Center RIKEN Brain Science Institute for technical assistance.

Correspondence should be addressed to Jun Aruga, Laboratory for Comparative Neurogenesis, RIKEN Brain Science Institute, Wako-shi, Saitama 351-0198, Japan. E-mail: jaruga@brain.riken.jp.

DOl:10.1523/JNEUROSCI.4046-06.2007

Copyright $\odot 2007$ Society for Neuroscience $\quad$ 0270-6474/07/275461-13\$15.00/0 caused by the human ZIC2 mutation (Brown et al., 1998). Zic2 belongs to the Zic family of zinc-finger TFs that control various processes of animal development (for review, see Aruga, 2004; Grinberg and Millen, 2005). In mammals, there are five Zicrelated genes that share highly conserved zinc finger domains. In terms of neural development, Zic1, Zic2, and Zic3 particularly draw our attention because their mouse mutants show marked, but distinct, neural phenotypes despite the structural similarity of these genes and their partly overlapping expression profiles.

Although the Zic2 mutant abnormalities are related to forebrain development, neither Zic1 nor Zic3 mutant mice show obvious forebrain abnormalities. Zicl-deficient mice show hypoplastic cerebellum and spinal cord (Aruga et al., 1998, 2002b). A quarter of Zic3-deficient mice show exencephaly (a form of neural tube defect) in regions such as the hindbrain (Carrel et al., 2000; Klootwijk et al., 2000; Purandare et al., 2002); however, the remaining individuals survive with a subtle phenotype in the cerebellum (Aruga et al., 2004). The involvement of Zicl in cerebellar development is also suggested in humans, in which ZIC1 is located in a genomic region deleted in the Dandy-Walker malformation (Grinberg et al., 2004). However, the involvement of $\mathrm{Zicl}$ and $\mathrm{Zic3}$ in forebrain development is possible, because both $Z i c 1$ are Zic3 are expressed markedly in the developing forebrain (Nagai et al., 1997).

To uncover the role of Zic1 and Zic3 in forebrain development, we characterized the forebrain anomalies in Zicl/Zic3 compound mutant mice. We show here that $Z i c 1$ and $Z i c 3$ are expressed at high levels in the telencephalic medial structures and cooperate in the expansion of neural precursors through the inhibition of cell cycle exit. Furthermore, on the basis of the doublemutant phenotype and a marker tracing analysis, we show the 
contribution of medial neuronal progenitors to olfactory bulb interneurons.

\section{Materials and Methods}

Mice. C57BL/6J and BALB/c mice were purchased from Nihon SLC (Shizuoka, Japan). Mutant mice heterozygous for Zic1 and Zic2 have been described previously (Aruga et al., 1998; Nagai et al., 2000). These mice were kept in a C57BL/6J background. The spontaneous mutation in the Bent tail (Bn) (Garber, 1952) mouse has been revealed to be a deletion of the X chromosome, including Zic3 (Carrel et al., 2000; Klootwijk et al., 2000). The phenotypes of Bn mice are very similar to those of Zic3deficient mice generated by targeted mutation (Purandare et al., 2002; Aruga et al., 2004). Bn mice were originally purchased from The Jackson Laboratory (Bar Harbor, ME). The mice were backcrossed four to six times with either $\mathrm{C} 57 \mathrm{BL} / 6 \mathrm{~J}$ or BALB/c mice. Both $\mathrm{C} 57 \mathrm{BL} / 6 \mathrm{~J}$ and BALB/c $B n$ mice were used for the initial characterization of external appearance and histological abnormalities. Because there were no clear differences in the forebrain phenotype of the compound mutant mice (data not shown), additional analyses were done in a mixed C57BL/6J by BALB/c background. (Zicl $+/-Z i c 3 B n / Y)$ males and $(Z i c 1+/-Z i c 3 B n /+)$ females were generated by mating $Z i c 3 B n /+$ females with $Z i c 1+/-$ males. Mating between $(\mathrm{Zicl}+/-Z i c 3 \mathrm{Bn} /+)$ females and $(\mathrm{Zicl}+/-$ $Z i c 3 B n / Y)$ males generated the compound mice (Zic1/3), lacking both Zic1 and Zic3 [males (Zic1-/-Zic3 Bn/Y) and females (Zic1-/-Zic3 $B n / B n)$ ]. Animals were maintained by the Research Resource Center, RIKEN Brain Science Institute (Saitama, Japan). All animal experiments were performed in accordance with the RIKEN guidelines for animal experiments. Every effort was made to minimize the number of animals used. Noon of the day on which vaginal plugs were first observed in the morning was defined as embryonic day 0.5 (E0.5). Zic1, Zic2, and Zic3 mutant alleles were genotyped according to the methods of Aruga et al. (1998), Nagai et al. (2000), and Franke et al. (2003), respectively.

Tissue preparation and histology. For histological examination, tissues were fixed in either Bouin's solution or $4 \%$ paraformaldehyde. After fixation, the tissues were dehydrated through graded alcohols, embedded in paraffin, sectioned at a thickness of $8-10 \mu \mathrm{m}$, and stained with cresyl violet.

In situ hybridization. In situ hybridization was performed using digoxygenin (DIG)-labeled cRNA probes, as described previously (Nagai et al., 1997). RNA probes for Zic1, Zic2, Zic3, and Wnt3a have been described previously (Takada et al., 1994; Nagai et al., 1997). Probes for Dlx1, Dlx2, Dlx5, GAD67, Hes5, Lhx6, Mash1, Neurogenin2 (Ngn2), Nkx2.1, ER81, Reelin, Slit1, Tbr1, Ttr, class III $\beta$ tubulin (Tubb3), and $\operatorname{Vax} 1$ were generated by reverse transcription-PCR. The sequences of the primers will be provided on request. Hybridization signals were detected with alkaline phosphatase-conjugated anti-DIG Fab fragments (Roche, Welwyn Garden City, UK), followed by color development with nitro blue tetrazolium and 5-bromo-4-chloro-3-indolyl-phosphate (Roche).

Immunofluorescence staining. Immunofluorescence staining was performed as described previously (Aruga et al., 1998; 2002a). Cryosections, $10-16 \mu \mathrm{m}$ thick, were subjected to analysis. The sections were washed three times with PBS and preincubated for $30 \mathrm{~min}$ in PBS containing 5\% normal goat serum and $0.1 \%$ Triton X-100 and then incubated in $1 \%$ normal goat serum and $0.1 \%$ Triton X-100 containing the following antibodies overnight at $4^{\circ} \mathrm{C}$. The primary antibodies were as follows: mouse anti-bromodeoxyuridine (BrdU) (Beckton Dickinson, Mountain View, CA), rat anti-BrdU (Abcam, Cambridge, UK), rabbit anti-GABA (Sigma, St. Louis, MO), rabbit anti-GFAP (Sigma), rabbit anti-green fluorescent protein (GFP) (Medical and Biological Laboratory, Nagoya, Japan), rat anti-GFP (Nacalai Tesque, Kyoto, Japan), mouse antimitogen-activated protein 2 (MAP2) (Sigma), mouse anti- $\beta$ III-tubulin (Promega, Madison, WI), mouse anti-Nestin (PharMingen, San Diego, CA), mouse anti-Ki67 (PharMingen), rabbit anti-Ki67 (YLEM, Rome, Italy), rabbit anti-Ki67 (Novocastra, Newcastle, UK), rabbit anti-Myc (Santa Cruz Biotechnology, Santa Cruz, CA), mouse anti-neuronspecific nuclear protein (NeuN) (Millipore, Temecula, CA), goat anti-olfactory marker protein (Wako, Osaka, Japan), rabbit anti-p75 (PharMingen), rabbit anti-tyrosine hydroxylase (TH; Millipore), guinea pig anti-Tbx21 (provided by Y. Yoshihara, RIKEN Brain Science Insti- tute), and rabbit anti-pan-Zic. Anti-pan-Zic antibodies were generated by immunization of rabbits with the glutathione $S$-transferase-Zic2 carboxyterminal region (amino acid numbers 416-530 in accession number NP_033600) and subsequent affinity purification by Medical and Biological Laboratory. It was confirmed by immunoblot analysis that this antibody recognized all of the Zic1, Zic2, and Zic3 proteins (data not shown). To detect these antibodies, Cy3- (Jackson ImmunoResearch, West Grove, PA), Alexa488-, and Alexa594-labeled secondary antibodies (Invitrogen, Eugene, OR) were used. Fluorescently labeled preparations were imaged under an Olympus (Tokyo, Japan) Fluoview FV300 confocal microscope or a Zeiss (Oberkochen, Germany) Axioskop2 plus microscope equipped with an AxioCam color CCD camera. All images were analyzed with Adobe (San Jose, CA) Photoshop CS software. For measurement of the numbers of neurons in the olfactory bulb (OB), four sets of wild-type mice, Zic1-/-, Zic3 Bn/Y (or Zic3 Bn/Bn), and Zic1-/$Z i c 3 B n / Y$ derived from four independent litters were used. Serial horizontal sections, $12 \mu \mathrm{m}$ thick, were prepared from E18.5 OBs and stained with Tbx21, TH, and GABA antibodies. For each OB, the immunoreactive cells on five serial sections that included the maximum diameter of the OB were counted. Statistical significance was determined by a $t$ test. Values of $p<0.05$ were considered significant.

Bromodeoxyuridine labeling. Pregnant female mice were injected intraperitoneally with $50 \mathrm{mg} / \mathrm{kg}$ BrdU (Roche) and killed either 1 or $24 \mathrm{~h}$ later. The detection was performed as described (Aruga et al., 1998). To measure the BrdU labeling index in the septum, three sets of wild-type mice, Zic1-/-, Zic3 Bn/Y (or Zic3 Bn/Bn), and Zic1-/- Zic3 Bn/Y (or Zic1 $-/-Z i c 3 B n / B n)$, derived from three litters, were used. To measure the cell cycle exit in the septum, wild-type $(n=5), Z i c 1-/-(n=4), Z i c 3$ $B n / Y($ or Zic3 Bn/Bn) $(n=5)$, and Zic1-/- Zic3 Bn/Y (or Zic1-/-Zic3 $B n / B n)(n=3)$ mice derived from three litters were analyzed. For the proliferation assays in the hippocampus, BrdU was injected $1 \mathrm{~h}$ before killing at E15.5, and wild-type $(n=4), Z i c 1-/-(n=4), Z i c 3 B n / Y$ (or $Z i c 3 B n / B n)(n=4)$, and Zicl-/- Zic3 Bn/Y (or Zic1-/-Zic3 Bn/Bn) $(n=3)$ mice derived from three litters were analyzed. For analyzing the cell cycle exit in the hippocampal ventricular zone, wild-type $(n=4)$, $Z i c 1-/-(n=4)$, Zic3 Bn/Y (or Zic3 Bn/Bn) $(n=3)$, and Zic1-/-Zic3 $B n / Y$ (or $Z i c 1-/-Z i c 3 B n / B n)(n=4)$ mice derived from four litters were used. In these analyses, the mean number of labeled cells was calculated from four to six comparable sections prepared from the septal area and hippocampus of each embryo. To calculate the labeling index, at least $100 \mathrm{Ki} 67+$ cells were first identified in a comparable area across each section, and then the BrdU-labeled cells among the Ki67+ cells were counted manually in each section. The cell fraction exiting the cell cycle in the BrdU-injected mice was measured as described previously (Chenn and Walsh, 2002; Depaepe et al., 2005). At least $100 \mathrm{BrdU}+$ cells were first selected, then Ki67+ cells in the BrdU + cells were counted for the analysis.

In utero electroporation. A cDNA fragment including the mouse Zic3 open reading frame was inserted into the EcoRI site of the pCS2+MT (myc tag) vector (Turner and Weintraub, 1994). Subsequently, the DNA fragment encoding the internal ribosomal entry site [IRES/enhanced GFP (EGFP)] (IE cassette) was excised from pIRES2-EGFP (Clontech, Palo Alto, CA) and inserted into the $3^{\prime}$ end of Zic 3 cDNA. The expression cassette myc-Zic3-IRES/EGFP was then excised and inserted into the EcoRI site of pCAG-GS (Niwa et al., 1991), which directs gene expression from the strong and ubiquitous CAG promoter (pCAG-Zic3-IE). The control vector, pCAG-EGFP, was generated by inserting the IRES/EGFP fragment into pCAG-GS. For the introduction of the DNA, each pregnant mouse was deeply anesthetized and a ventral midline incision was made to perform in utero manipulation. pCAG-Zic3-IE $(5 \mu \mathrm{g})$ containing $0.01 \%$ fast green as a tracer was injected through the uterine wall with a glass micropipette into the telencephalic vesicle of each embryo in utero. One microgram of pCAG-EGFP was also coinjected with pCAG-Zic3-IE in many cases because it facilitates the identification of EGFP + cells. For the controls, $5 \mu \mathrm{g}$ of pCAG-EGFP was injected. The volume of the injected DNA solution was kept minimal (typically $1 \mu \mathrm{l}$ ). After injection, electroporation was performed as described previously (Ohtsuka et al., 2001). A CUY21 electroporator (Tokiwa Science, Fukuoka, Japan) was used to deliver four $50 \mathrm{~ms}$ pulses of $35 \mathrm{~V}$ at $950 \mathrm{~ms}$ intervals. Embryos or 

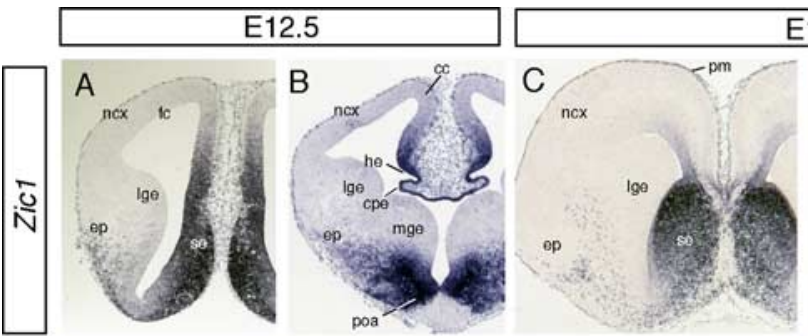

E16.5

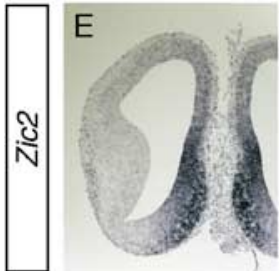

F
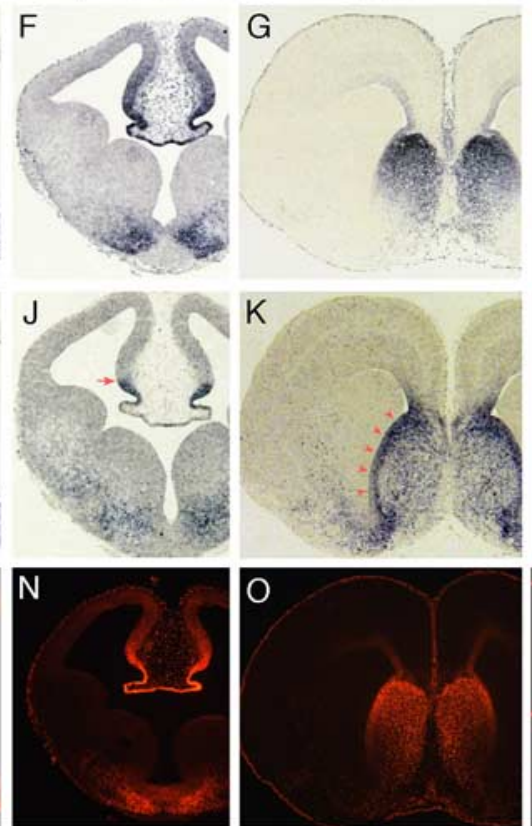
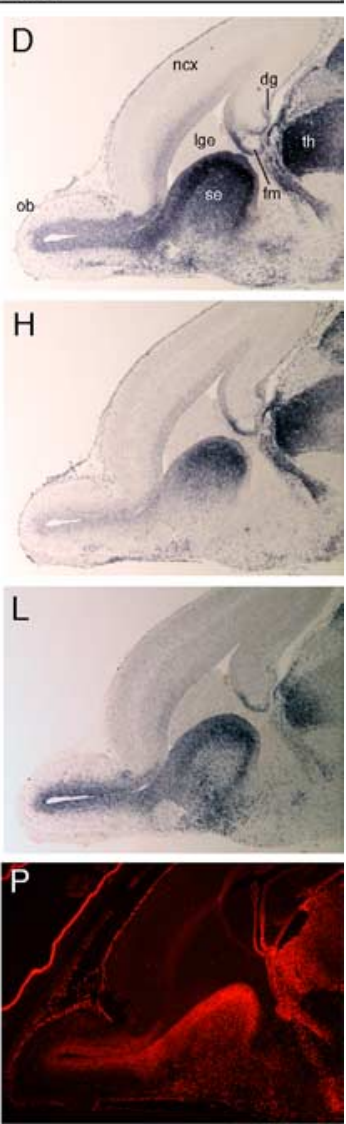

Figure 1. Locations of mouse Zic1, Zic2, and Zic3 mRNA, and Zic protein in the developing telencephalon. $\boldsymbol{A}-\boldsymbol{L}$, In situ hybridization for Zic $1(\boldsymbol{A}-\boldsymbol{D})$, Zic2 $(\boldsymbol{E}-\boldsymbol{H})$, and Zic3 (I-L) mRNA was performed on coronal $(\boldsymbol{A}-\boldsymbol{C}, \boldsymbol{E}-\boldsymbol{G}, \boldsymbol{I}-\boldsymbol{K})$ and sagittal $(\boldsymbol{D}, \boldsymbol{H}, \boldsymbol{L})$ sections at E12.5 $(\boldsymbol{A}, \boldsymbol{B}, \boldsymbol{E}, \boldsymbol{F}, \boldsymbol{I}, \boldsymbol{J})$ and $\mathrm{E} 16.5(\boldsymbol{C}, \boldsymbol{D}, \boldsymbol{G}, \boldsymbol{H}, \boldsymbol{K}, \boldsymbol{L}) . \boldsymbol{A}, \boldsymbol{E}, \boldsymbol{I}, \boldsymbol{B}, \boldsymbol{F}, \boldsymbol{J}, \mathrm{Adjacent}$ rostral $(\boldsymbol{A}, \boldsymbol{E}, \boldsymbol{I})$ and caudal $(\boldsymbol{B}, \boldsymbol{F}, \boldsymbol{J})$ parts of serial coronal sections. Zic1 and Zic2 mRNAs are broadly distributed in the septum, dorsomedial part of the telencephalon, and dorsal thalamus. Zic3 mRNA is in the VZ/SVZ of the ventral telencephalon (I, $\boldsymbol{K}$, red arrowheads) and the medial marginal region of the cerebral cortex (cortical hem) with a clear boundary (J, arrow). Ventral expression of Zic 1 and Zic3 extends laterally $(\boldsymbol{A}, \boldsymbol{C}, \boldsymbol{I}, \boldsymbol{K})$. $\boldsymbol{M}-\boldsymbol{P}$, Immunofluorescence staining of Zic proteins is shown in coronal $(\boldsymbol{M}-\mathbf{0})$ and sagittal $(\boldsymbol{P})$ sections at E12.5 $(\boldsymbol{M}, \boldsymbol{N})$ and E16.5 $(\boldsymbol{O}, \boldsymbol{P})$. cc, Cingulate cortex-forming area; cpe, choroid plexus; $\mathrm{dg}$, dentate gyrus of hippocampus; ep, entopeduncular area; fc, frontal cortex-forming area; fm, fimbria of hippocampus; he, cortical hem; Ige, lateral ganglionic eminence; mge, medial ganglionic eminence; ncx, neocortex (cerebral cortex); ob, olfactory bulb; pm, primitive meninx; poa, preoptic area; th, thalamus; se, septum.

neonates were harvested 3-10 d after electroporation. Four independent experiments were performed. For quantitative analysis, all EGFP + cells (at least 100) in comparable radial segments encompassing the entire cerebral cortex layer were counted for pCAG-Zic3-IE- and pCAG-EGFPelectroporated specimens. The numbers of GFAP-, Ki67-, NeuN-, MAP2-, or Nestin-producing cells in the total number of EGFP+ cells were counted. We observed misexpression of $\mathrm{Zic} 3$ without myc tag result in similar results, excluding the possibility that the myc epitope affected the function of $\mathrm{Zic} 3$ (data not shown). For directional in utero electroporation into the medial telencephalon, DNA solution (pCAG-EGFP) was injected into the telencephalic vesicles at E13.5. The DNA-injected embryos were held by electrodes, with the anode medially to direct the current toward the medial structures, and received the electrical pulses. The embryos were allowed to develop normally and fixed at postnatal day 4. The site of transfection were confirmed to be in the desired regions for the animals subjected for the analysis. The transfection site was defined as a massively EGFP expressing region facing the ventricular surface where the dye-containing DNA solutions had been placed. Such regions were always observed at 1 to $10 \mathrm{~d}$ after electroporation in the all electroporated, EGFP-expressing embryos $(>50)$. The definition could miss a region containing very rapidly leaving cells without any traces in the $\mathrm{VZ}$ if such cells existed. However, this situation seems unlikely because the electroporated cells can be detectable in the VZ even more than 1 month after electroporation into GE (Nakahira et al., 2006) and the pCAG-GS can maintain gene expression 3 weeks after electroporation (Saito and Nakatsuji, 2001).

\section{Results}

$Z i c 1$ and $Z i c 3$ are expressed in the dorsal and ventromedial telencephalon To determine the spatial correlations of Zicl and Zic3 expression profiles, we first performed in situ hybridization in E12.5 and E16.5 forebrain sections (Fig. 1; supplemental Fig. 1, available at www. jneurosci.org as supplemental material). Adjacent sections were used for reference, indicating the Zic2 transcript distribution and immunofluorescence staining using anti-pan Zic antibody that recognized all of the three Zic proteins. In the rostral part of the E12.5 telencephalon (Fig. 1A,E,I), Zic1, Zic2, and Zic3 were all strongly expressed in both the ventricular and mantle zones of the septal area. Weak expression of Zic1 and Zic3 was detected in the entopeduncular area (Fig. $1 A, I$ ), and of $Z i c 2$ in the dorsal telencephalon (Fig. 1E). In the more caudal parts (Fig. $1 B, F, J$ ), strong Zicl expression was detected in the preoptic area, where moderate expression of Zic2 and Zic3 overlapped. Zic1 and Zic3 expression in the preoptic area extended laterally to include the entopeduncular area. Another overlap of the three genes was observed dorsomedially in the marginal neuroepithelium adjacent to the choroids plexus, and in the intermediate epithelium known as the cortical hem (Grove et al., 1998). Well-demarcated expression of Zic3 was observed in the cortical hem (Fig. 1J; supplemental Fig. 1G, available at www.jneurosci.org as supplemental material) and persisted until birth (supplemental Fig. $1 \mathrm{H}, \mathrm{I}$, available at www. jneurosci.org as supplemental material) (data not shown). From this region, Zicl expression extended dorsally into the cingulated cortex-forming area, and Zic2 transcript was detected more broadly in the ventricular layer of the frontal cortex-forming area (Fig. $1 F$ ).

In the E16.5 telencephalon, Zic1, Zic2, and Zic3 were commonly expressed in the septum and hippocampus. In the septum, $Z i c 1$ and $Z i c 2$ expression occurred broadly (Fig. $1 C, G$ ) whereas $Z i c 3$ expression was enhanced in the VZ/subventricular zones (SVZs) (Fig. $1 \mathrm{~K}$ ). Both Zicl and Zic3 expression extended laterally (Fig. $1 C, K$ ), as in the E12.5 sections, and continued rostrally to the $\mathrm{VZ}$ in the $\mathrm{OB}$ (Fig. 1D,L). Expression in the hippocampal primordia varied among the three Zic genes. Zic3 expression in the hippocampal primordia was notably limited to the ventricular layer of the fimbria (Fig. $1 \mathrm{~L}$; supplemental Fig. $1 G-I$, available at www.jneurosci.org as supplemental material), whereas Zic1 and $Z i c 2$ expression was detected in the hippocampal fissure in addition to the ventricular layer of the fimbria (Fig. $1 D, H$, supplemental Fig. $1 A-F$, available at www.jneurosci.org as supplemental material). 
The distributions of Zic proteins at these stages seemed very similar to the summation of the Zic1, Zic2, and Zic3 mRNA distribution (Fig. $1 M-P$ ). However, a mediolateral gradient of the immunopositive signal (stronger on the medial side) in the ventricular layer of the cerebral cortex was clear in the coronal sections of both stages (Fig. $1 \mathrm{M-O}$, supplemental Fig. $1 J-L$, available at www. jneurosci.org as supplemental material). Immunopositive signals in the primitive meninx surrounding the whole telencephalon corresponded to the Zic1 and Zic2 mRNA distribution. It should be noted that $\mathrm{Zic}$ proteins were not markedly detected in the VZ or SVZ of the lateral (LGE) and medial ganglionic eminences (MGE) at these stages and later (Fig. $1 M-O)$ (data not shown).

The above analysis revealed that Zic1 and $Z i c 3$ transcripts were abundant in the $\mathrm{OB}$, but the Zic2 transcript was scarce. We further examined the distribution of the Zic1 and Zic3 transcripts and Zic proteins in horizontal sections of the $\mathrm{OB}$ taken on $\mathrm{P} 0$, when the layer organization of the $\mathrm{OB}$ had become clear. Expression of Zicl and $Z i c 3$ was detected in the VZ, in the presumptive glomerular layer (Fig. $2 A, B$, open arrows), and weakly in the granule cell layer (Fig. $2 A, B$, solid arrows). The layer identity was confirmed in adjacent sections by the colocalization of Dlx2 (Fig. 2C) and GAD67 (Fig. 2D) transcripts, which labeled the same glomerular and granule cell layers, and its location neighboring the Reelin (Fig. 2E) signal, which demarcates the mitral cell layer. Expression of Zicl and Zic3 in the OB VZ was continuous with that in the septum through medial expression in the base of the OB (Fig. $2 A, B$, red arrowheads), whereas $D l \times 2$ was expressed on both the medial and lateral sides, which were respectively continuous with the septum and the ganglionic eminences (GEs) (Fig. 2C, red arrowheads). Immunofluorescence staining revealed the distribution of Zic proteins in the cell nuclei around the glomeruli, suggesting that $Z i c 1$ and $Z i c 3$ are expressed in the periglomerular interneurons (Fig. $2 F, G$ ). We found that expression of Zicl and Zic3 in the glomerular and granule cell layer persisted thereafter into adulthood (data not shown).

\section{Forebrain defects in Zic1/Zic3 mutant mice}

To study the effects of Zicl and Zic3 deficiency on forebrain development, we first performed $Z i c 1+/-\times Z i c 3 B n /+$ intercrosses to generate transheterozygotes [heterozygous $Z i c 1$ mutant allele together with heterozygous Zic3 mutant allele $(Z i c 1+/-Z i c 3 B n /+)]$. The transheterozygotes were mated with $(Z i c 1+/-Z i c 3 B n / Y)$ to generate Zicl/Zic3-deficient animals [i.e., mice homozygous for the Zic1 mutant allele and hemizygous (Zic1-/-Zic3 Bn/Y) or homozygous (Zic1-/-Zic3 Bn/ $B n)$ for $Z i c 3$; hereafter we call these genotypes collectively the "Zicl/3 mutant"].

Examination at E18.5 revealed that Zic1/3 mutants were recovered nearly at the expected Mendelian ratio $[13.4 \%$ Zic1/3; the expected ratio was $12.5 \%(n=164)]$ and the frequency of exencephaly was $32 \%$, which was not significantly different from that in $Z i c 3 B n / Y$. We therefore considered that the addition of Zicl
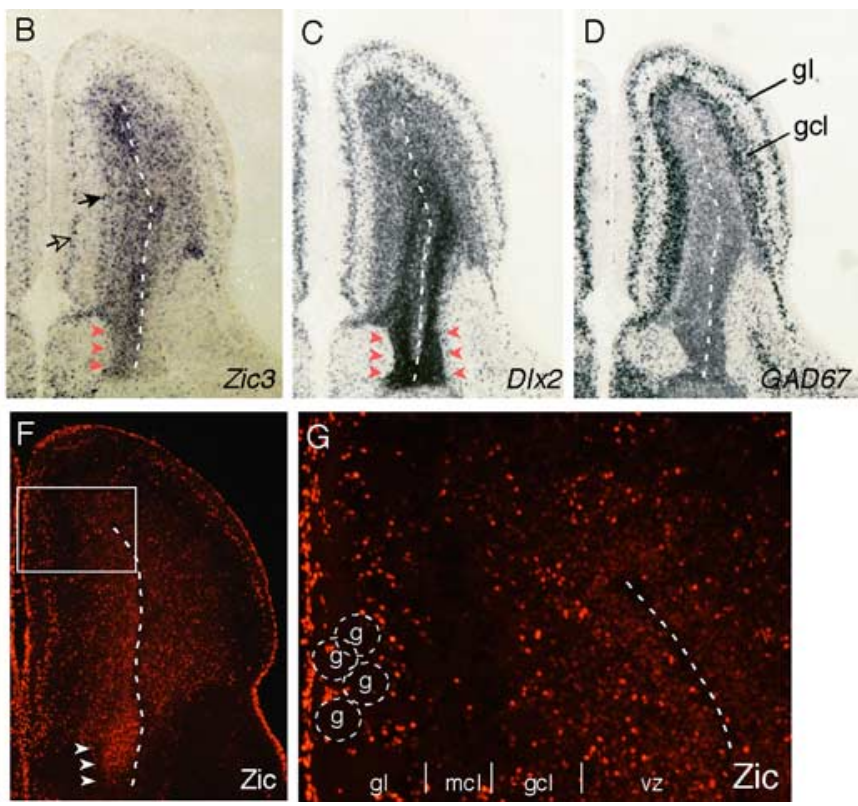

Figure 2. Expression patterns of Zic1 and Zic3 mRNA and pattern of production of Zic protein in the OB. A-G, Distributions of ( lines, remnant of olfactory vesicle. g, Glomeruli (some marked by broken circles); gcl, granule cell layer; gl, glomerular layer; $\mathrm{mcl}$,

mutations to the Zic3-deficient mice did not affect the frequency of occurrence of neural tube defect, and we analyzed the remaining embryos. In external appearance, E18.5 Zicl/3 embryos were slightly smaller than their wild-type littermates and had a dented hindbrain and kinky tail (Fig. 3A).

The outer and histological appearances of the Zic1/3 forebrain seemed normal by E12.5, but were distinguishable from wildtype at E14.5 (Figs. 4, 5) (data not shown). At E18.5, the Zic1/3 forebrain was characterized by its small OBs, with a wide space between the left and right OBs (Fig. 3C). Cresyl violet-stained coronal sections at E17.5 revealed various abnormalities in $\mathrm{Zicl} / 3$, whereas the $\mathrm{Zic1}-/-$ and $\mathrm{Zic3Bn} / \mathrm{Y}$ brains were almost indistinguishable from the wild type (Fig. 3D-O). In the rostral part of Zic1/3, the septum was markedly small and the corpus callosum failed to form an obvious interhemispheric connection at the midline (Fig. 3G) (data not shown). At a more caudal level, the mediolateral extension of the dorsal thalamus and hippocampus were smaller, and the cerebral cortex was thinner than in the wild type (Fig. $3 K$ ). In higher-magnification views (Fig. 3O), the dentate gyrus of the hippocampus and the fimbria were smaller, whereas the layer organization of the hippocampus was largely maintained.

\section{Dorsomedial forebrain structure is disorganized in Zic1/Zic3 mutant mice}

To characterize the regional defects in the $Z i c 1 / 3$ mutant, we first examined molecular marker expression in the Zic1/3 dorsal telencephalon at E14.5 with a littermate control [ $\mathrm{Zic1}-/-$, which gave nearly identical results to the wild type (data not shown)] and a Zic2 hypomorphic mutant $(Z i c 2 k d / k d)$ as references (Fig. 4). Neurogenin2 (Ngn2; a proneural bHLH gene expressed in dorsal neural progenitors) (Nieto et al., 2001) and Tbr1 (T-box brain gene expressed in neurons of the cortical preplate and subplate) (Dwyer and O'Leary, 2001) showed altered expression patterns in 



Figure 3. Forebrain defects in Zic1/3 embryos. A, Zic1/3 mutant (Zic1 - / - Zic3 Bn/Y, right) is slightly smaller than Zic1-/(indistinguishable from wild type, left) at E18.5, and shows dented hindbrain and kinky tail. $\boldsymbol{B}, \boldsymbol{C}$, Frontal views of the brains at E18.5. The forebrain of Zic $1 / 3(\boldsymbol{C})$ is smaller than that of Zic $1-/-(B)$, and the left and right $0 B$ s of Zic1/3 are positioned with a wide interspace (arrowheads). D-0, Cresyl violet-stained coronal sections of E17.5 brains from wild type (Zic1 $+/+Z i c 3+/ Y$; $\boldsymbol{D}$,

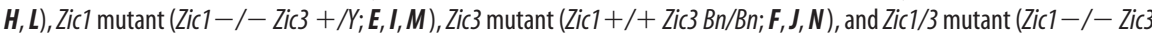
$B n / B n ; \boldsymbol{G}, \boldsymbol{K}, \mathbf{O}) . \boldsymbol{D}-\mathbf{G}$ and $\boldsymbol{H}-\boldsymbol{K}$ are comparable rostral and caudal sets of sections, respectively. $\boldsymbol{L}-\mathbf{O}$ are higher-magnification views of the hippocampus in $\boldsymbol{H}-\boldsymbol{K}$, respectively. Comparison reveals hypoplasia or altered tissue architecture of the septum $(\boldsymbol{G})$, corpus callosum $(\boldsymbol{G})$, thalamus $(\boldsymbol{K})$, cerebral cortex $(\boldsymbol{G}, \boldsymbol{K})$, hippocampus $(\boldsymbol{K}, \mathbf{0})$, and choroid plexus $(\boldsymbol{G}, \boldsymbol{K}, \mathbf{0})$. III, Third ventricle; $C A 1$, hippocampal field CA1; CA3, hippocampal field CA3; cc, corpus callosum; cpe, choroid plexus; dg, dentate gyrus; dt, dorsal thalamus; fm, fimbria; hip, hippocampus; ht, hypothalamus; Ige, lateral ganglionic eminence; ncx, neocortex (cerebral cortex); $s$, subiculum; sep, septum; st, striatum.

the dorsomedial aspect (including the hippocampus-forming region) of the cerebral cortex in Zic1/3 (Fig. 4B,E,H), whereas there were no clear changes in the dorsolateral aspect of the cerebral cortex. In the medial part, the thickness of the Ngn2expressing layer was irregular and asymmetric (Fig. $4 B, E$ ), and the Tbr1-expressing layer was thicker than in Zicl-/- (Fig. 4H).
Consistent with these observations, expression of Hes5, expressed specifically by neuroepithelial precursors (Ohtsuka et al., 1999), and the neural-specific Tubb3 (Burgoyne et al., 1988) showed the irregular proliferation layer and locally increased differentiation of the neural precursors in these regions (supplemental Fig. $2 F, G$, available at www.jneurosci.org as supplemental material). The region expressing the medial pallium-specific marker Ttr (a thyroxine/retinol-transport protein in choroid plexus cells) and Wnt $3 a$ (specifically expressed in cortical hem) (Grove et al., 1998) was reduced in size (Fig. $4 K, N$ ). The reduction in size of the choroid plexus, which produces CSF, may account partly for the collapsed appearance of the lateral ventricles in the $Z i c 1 / 3$ forebrain (Figs. 3-5).

It is known that $Z i c 2 k d / k d$ also shows forebrain malformations (Nagai et al., 2000). Therefore, we compared the forebrain anomalies of $\mathrm{Zicl} / 3$ with those of $Z i c 2 k d / k d$. Although the severity of the dorsal forebrain defects of Zic2 $k d / k d$ varied over a range (data not shown), the dorsal marker expression patterns of a mild case (Fig. $4 C, F, I, L, O$ ) were similar to those of $\mathrm{Zic1/3}$ : disorganized expression of $N g n 2$ and Tbr1, and reduced expression of Ttr and Wnt3a. These similarities suggest that Zic1, Zic2, and Zic3 are involved in establishment of the dorsomedial forebrain structures in an analogous manner.

\section{Ventral forebrain defects and reduction in numbers of septum-derived neurons in the Zic1/Zic3 mutant}

We next used molecular markers to examine defects in the ventral aspect of the rostral telencephalon (Fig. 5). Staining with Dlx2 (a marker for the ventral ventricular layer of the septum and GEs) (Eisenstat et al., 1999) and Slit1 (a marker for the medial septum, GEs, and cortical plate) (Nguyen Ba-Charvet et al., 1999) probes revealed a hypoplastic septum (Fig. $5 C, D$ ) in $Z i c 1 / 3$ at E14.5 and an unusual expansion of the septal VZ and SVZ at E17.5 (Fig. 4I, red arrowheads). Similarly, staining of septum and ventral forebrain progenitors with Dlx1 (Anderson et al.,1997b), Dlx5 (Long et al., 2003), Mash1 (Casarosa et al., 1999), Vax1 (Soria et al., 2004), and ER81 (Stenman et al., 2003) showed medial expansions of the marker genes expressing regions, suggesting the altered characteristics of the septal VZ/SVZ at E15.5-E18.5 (supplemental Fig. 3H-M, available at www.jneurosci.org as supplemental material) (data not shown). In the Zic1/3 mutant, expression of Dlx2 was unexpectedly reduced in part of the LGE where $Z i c s$ are not expressed (Fig. 5I, clear arrowheads). We speculated that the reduction in 
the secretory epithelium may have affected the cell properties of this region. Immunofluorescence staining with a neuronal marker, anti-MAP2 antibody (Fig. $4 J$ ), and GAD67 mRNA staining (supplemental Fig. $3 N$, available at www. jneurosci.org as supplemental material) also demonstrated hypoplasia of the septum during E14.5 to E18.5. Staining with anti-p75 antibody, which labels cholinergic neurons in the medial septum, revealed that the number of p75-positive cells was greatly reduced in the Zicl/3 medial septum (Fig. $5 K, L$ ). ChAT-positive cholinergic neurons were also reduced in number (data not shown). These observations indicate that Zic1 and Zic3 are essential for expansion and region-specific differentiation (regionalization) of the septum.

\section{Abnormal differentiation of progenitor cells in the basal telencephalon}

The marker study revealed that $\mathrm{Zic1/3}$ mutants have deficits in both the dorsal and ventral medial telencephalic structures. To test whether this was attributable to a defect in progenitor proliferation or to a defect in differentiation, we performed cell cycle analyses of the mutant and wildtype septum at E12.5 to E13.5 (Fig. 6). To quantify the fraction of cells in S phase, we obtained a BrdU-labeling index by counting the number of cells that were labeled by a single pulse of BrdU (Fig. 6A-H) as a percentage of the total number of proliferating cells that were identified by Ki67 immunoreactivity. Because the length of the $S$ phase remains relatively constant in mammalian cells (DiSalvo et al., 1995), this labeling index provides an estimation of the cell cycle length (Chenn and Walsh 2002). Examination of the septal region of wild-type, Zic1-/-, Zic3 Bn/Y, and the Zic1/3 mutant at E13.5 (Fig. 6A-H) showed that there were no significant differences in the BrdU-labeling index among the four groups (Fig. 6Q), suggesting that Zic1/3 neural progenitors proliferate at a rate comparable with those in the wild-type and the single mutants. Programmed cell death (apoptosis) occurs during normal development of the CNS, and increased cell death could be an explanation for the decrease size of the septal region of $Z i c 1 / 3$ mutant embryos. However, comparisons of the TUNEL (terminal deoxynucleotidyl transferasemediated biotinylated UTP nick end labeling)-stained sections showed no differences in the cell death frequency between $\mathrm{Zic1/3}$ and wild-type embryos (data not shown).

Another explanation for the cell number reduction would be a shift in the fraction of progenitors that choose to remain proliferating instead of differentiating. To address this possibility, we next examined cell cycle exit and re-entry by examining BrdU/ Ki67-double-stained sections $24 \mathrm{~h}$ after the BrdU pulse labeling. Cells that had left the cell cycle were identified as BrdU+ and $\mathrm{Ki} 67-$, and cells that remained in the cell cycle were BrdU + and
$\mathrm{Ki} 67+$. At E13.5, we found a slight but significant increase (10 to $14 \% ; n=3 ; p<0.05$ by $t$ test) in the cell cycle-exiting proportion of the $Z i c 1 / 3$ progenitors in comparison with those in the wildtype, Zic1-/-, or Zic3 Bn/Y (Fig. $6 I-K, M-O, R$ ). In accordance with the cell cycle analysis, a greater number of differentiated neural cells stained by class III $\beta$ tubulin were detected in $Z i c 1 / 3$ than in Zicl-/- (Fig. $6 L, P$ ). These results indicated that premature differentiation was a cause of the septal hypoplasia in Zic1/3.

Building on the above results, we additionally examined proliferation and differentiation in the hippocampal primordium (supplemental Fig. 4, available at www.jneurosci.org as supplemental material). The number of BrdU-positive cells was decreased strongly in the fimbria, and slightly in the hippocampal ventricular zone in the Zic1/Zic3 mutant at E15.5 compared with those in wild-type, Zicl-/- and Zic3 Bn/Y (supplemental Fig. $4 B, I$, available at www.jneurosci.org as supplemental material) (data not shown). The cell cycle-exiting proportion in the E14.5 

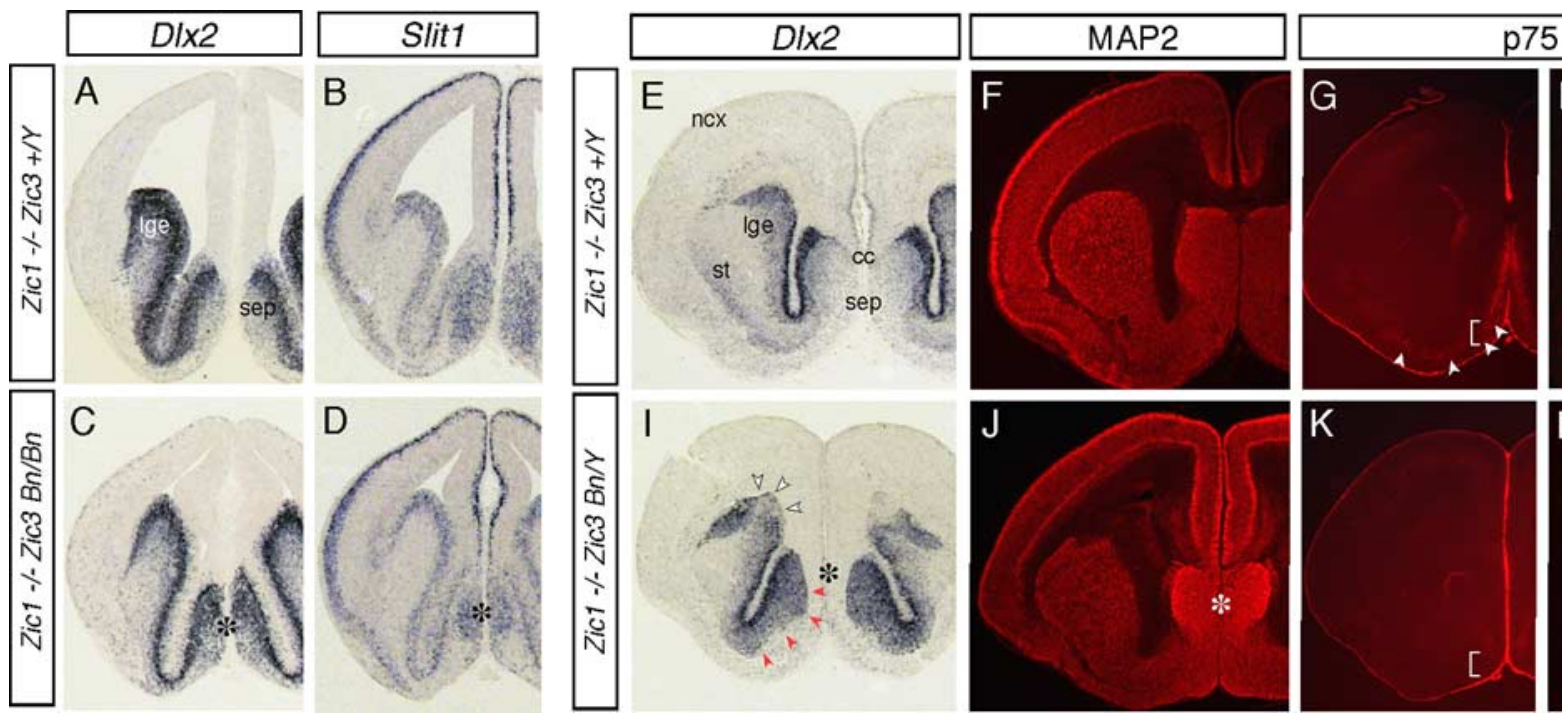

\section{5}

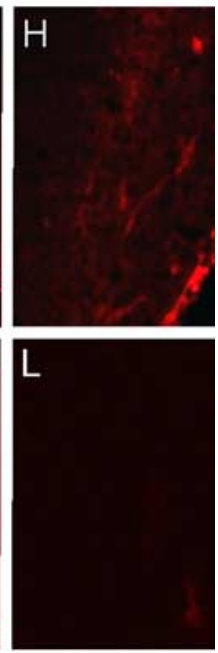

Figure 5. Defective septal structures in the Zic1/3 mutant. $A-L$, Coronal sections of the Zic1 mutant (Zic1 - / - Zic3 $+/ Y ; A, B, E-H)$, and Zic1/3 double mutant (Zic1 - / - Zic3 Bn/Y; C, D, I-L) at E14.5 (A-D), E15.5 $(\boldsymbol{G}, \boldsymbol{H}, \boldsymbol{K}, \boldsymbol{L})$, and E18.5 $(\boldsymbol{E}, \boldsymbol{F}, \boldsymbol{I}, \boldsymbol{J})$ are shown. In situ hybridization for Dlx2 $(\boldsymbol{A}, \boldsymbol{C}, \boldsymbol{E}, \boldsymbol{I})$ and $\operatorname{Slit}(\boldsymbol{B}, \boldsymbol{D})$, and immunofluorescence staining for MAP2 $(\boldsymbol{F}, \boldsymbol{J})$ and p75 $(\boldsymbol{G}, \boldsymbol{H}, \boldsymbol{K}, \boldsymbol{L})$ were performed on brain coronal sections. Asterisks in $\boldsymbol{C}, \boldsymbol{D}, \boldsymbol{I}$, and $\boldsymbol{J}$ indicate hypoplastic septum. Red arrowheads in $I$ indicate unusual expansion of $D / x 2$ in the septal region of the Zic $1 / 3$ mutant. 0 pen arrowheads in $\boldsymbol{I}$ indicate area of $D / x 2$ signal reduction of unknown cause (e.g., change secondary to ventricular collapse). White arrowheads in $\boldsymbol{G}$ indicate $\mathbf{p} 75$-positive neurons. $\boldsymbol{H}$ and $\boldsymbol{L}$ are higher-magnification views of areas indicated in $\boldsymbol{G}$ and $\boldsymbol{K}$, respectively. p75-positive cholinergic neurons are reduced in number (or not detected) in the medial septum. cc, Corpus callosum, Ige, lateral ganglionic eminence; $n c x$, neocortex; se, septum. st, striatum.

hippocampal ventricular zone was slightly, but significant higher (15.0 to $25.1 \%$ ) in the Zic1/3 than the wild-type, Zic1-/-, or Zic3 $B n / Y$ (supplemental Fig. $4 H, J$, available at www. jneurosci.org as supplemental material) (data not shown). Cell death frequencies were not significantly changed in these preparations (data not shown). Together, these observations demonstrated that Zicl and Zic3 are essential for expansion and regionspecific differentiation of the neuronal precursors both in septal and hippocampal primordia.

\section{Misexpression of Zic3 maintains undifferentiated cells in the ventricular zone of the embryonic telencephalon}

The above results indicate that $Z i c 1$ and $Z i c 3$ are involved in the regulation of neuronal progenitor differentiation. To further investigate their functions in neuronal differentiation, we performed a gain-of-function experiment. Zic3/EGFP-expressing plasmid or control EGFP-expressing plasmid was injected into the ventricle of the telencephalon and transfected plasmid DNA into the telencephalic cells by electroporation (Fig. 7). The plasmid was transfected at E14.5, and $3 \mathrm{~d}$ after (E17.5), the position and shape of the transfected cells were examined by their fluorescence. When EGFP alone was expressed, many of the EGFP+ cells were located out of the VZ with radially oriented processes, suggesting that they radially migrated from the VZ after electroporation (Fig. $7 A-D)$. Some of their cell bodies reached the cortical plate and subplate and expressed the neuronal marker MAP2 (Fig. 7C), indicating that many of the ventricular cells had undergone neuronal differentiation in the E14.5 to E17.5 period. In contrast, when Zic3 was misexpressed together with EGFP, the cell bodies of almost all transfected cells $(\mathrm{EGFP}+)$ remained in the VZ (Fig. 7E). These transfected cells were negative for MAP2 (Fig. 7G), but expressed Nestin, a marker of neuronal progenitor cells (Fig. 7F). Quantification of each cell type in the sections demonstrated that whereas 34\% of the control EGFP-transfected cells became MAP2 + neurons, only $12 \%$ of the Zic3-transfected cells did (Fig. 6I). In addition, Nestin-positive cells were more frequently observed in the Zic3-misexpressed cells than in the control cells. The proportion of the proliferating cells with Ki67 immunoreactivities was significantly increased in the Zic3transfected cells compared with the control cells (Fig. 7D,H), although the frequencies of cell death were not affected by the Zic3-misexpression (data not shown). These results indicate that Zic3 can inhibit neuronal differentiation and maintain proliferating neuronal progenitors.

To determine the later fates of Zic3-misexpressed cells, we also transfected Zic3 at E14.5 and examined the EGFP+ cells at P4. When EGFP alone was introduced by electroporation, $>60 \%$ of the EGFP + cells migrated into the cortical plate and differentiated into mature neurons that expressed MAP2 + and NeuN+ (supplemental Fig. 4A,B,G, available at www.jneurosci.org as supplemental material). In contrast, when Zic3 together with EGFP was introduced, 20-30\% of the EGFP + cells differentiated into MAP2 + and NeuN + neurons, but $38 \%$ of the EGFP + cells remained in the VZ/SVZ and differentiated into GFAP + cells (supplemental Fig. 4F, G, available at www.jneurosci.org as supplemental material). These results indicate that Zic3misexpressed cells tend to remain as GFAP + cells, supporting the previous idea that the neuronal differentiation of the precursors is inhibited by Zic3.

\section{Reduced interneuron production in the olfactory bulb of Zic1/Zic3 mutants}

Expression of $Z i c 1$ and $Z i c 3$ is prominent in the medial telencephalon, and their expression extended into the OB (Fig. 1,2). Loss of both $Z i c 1$ and Zic3 function resulted in hypoplasia of the septum (Figs. 3, 5, 6). In the Zic1/3 basal telencephalon, a discernible phenotype, in addition to that of the septum, appeared in the OB. Cresyl violet-staining at E18.5 showed that the Zic1/3 OB lacked the distinct neuronal layers that could be seen in the wild-type $O B$ (Fig. $8 \mathrm{~K}$ ). Horizontal sections including the adjacent structures revealed that most of the Zic1/Zic3 olfactory axons failed to reach the $\mathrm{OB}$ and formed a large, tangled sphere between the olfactory epithelium and $\mathrm{OB}$ (Fig. $8 D, E$, asterisks). This structure was similar to the "fibrocellular mass" identified previously in Gli3 mu- 
tants $(X t / X t)$ (St John et al., 2003) and Arx-knock-out mice (Yoshihara et al., 2005). Only a small fraction of the olfactory axons were in contact with the medial surface of the OB (data not shown).

To test whether the deficit in $\mathrm{OB}$ was caused by a defect in the proliferation of $\mathrm{OB}$ neuronal progenitors, we performed a BrdU-labeling assay at E15.5 and E17.5, when the majority of the OB local interneurons were generated (Hinds, 1968a,b, 1972a,b). One hour after a pulse of BrdU at E15.5, we identified the location of BrdU-positive cells in the horizontal sections of wild-type littermates and $\mathrm{Zicl}$, Zic3, and Zic1/3 mutants (Fig. 8C,F) (data not shown). At each of these stages, the number of BrdU-positive cells in the VZ and SVZ in the Zic1/3 mutant $(n=124 \pm$ 31) was significantly lower than in the wild type $(n=365 \pm 39)$, Zicl $-/-(n=379 \pm$ 46 ), or $Z i c 3 B n / Y$ or $Z i c 3 B n / B n$ ( $n=$ $351 \pm 52$ ), suggesting that Zic1 and Zic3 deficiency reduced the number of proliferating neuronal progenitors to one-third that of the wild type at E15.5.

To assess the development of the $\mathrm{OB}$ projection neurons (mitral/tufted cells), we examined the distribution of Tbx21, which is specifically expressed in these cells in the OB (Faedo et al., 2002; Yoshihara et al., 2005). In the wild-type, Zic1-/-, and Zic3 -/- OB, anti-Tbx21 staining clearly demarcated the mitral cell layer with a thickness of 2-4 mitral cells at E18.5 (Fig. $8 H$ ) (data not shown). In contrast, in the Zic1/3 OB, Tbx21-stained cells were detected as a thicker layer (Fig. $8 \mathrm{~L}$ ) with a slight reduction (by $\sim 22 \%$ ) in the number of Tbx21-positive mitral cells (Fig. 8O). For the analysis of OB interneurons (granule and periglomerular neurons), TH (Fig. 8I,M) and GABA (Fig. $8 \mathrm{~J}, \mathrm{~N})$ were detected by specific antibodies. In the $\mathrm{OB}, \mathrm{TH}$ marks a subset of granule and periglomerular dopaminergic cells (Kosaka et al., 1995; Toida et al., 2000; Baker et al., 2001). In the Zic1/3 mutant, the TH signal was almost eliminated from the region corresponding to the granule cell layer and was reduced in the glomerular layer (Fig. 8M,O). In the control littermate $\mathrm{OB}, \mathrm{GABA}$ immunoreactivity was detected in both granule cells and periglomerular cells (Fig. 8J), as has been reported (Behar et al., 1994). In Zic1/3, however, there was a severe reduction in the number of GABApositive neurons (reduced to $\sim 27 \%$ ) (Fig. $8 N, O$ ). As a consequence, the $\mathrm{Zicl} / 3$ mutation decreases the proportion of neuronal progenitors in the $\mathrm{OB}$, and this decrease in cell numbers was most severe in the $\mathrm{TH}+$ and $\mathrm{GABA}+\mathrm{OB}$ interneurons. Although there was a decrease in the numbers of these cells, the layer organization seemed to be partially maintained in several cases. Thickening septum. ${ }^{*} p<0.05$ by $t$ test.
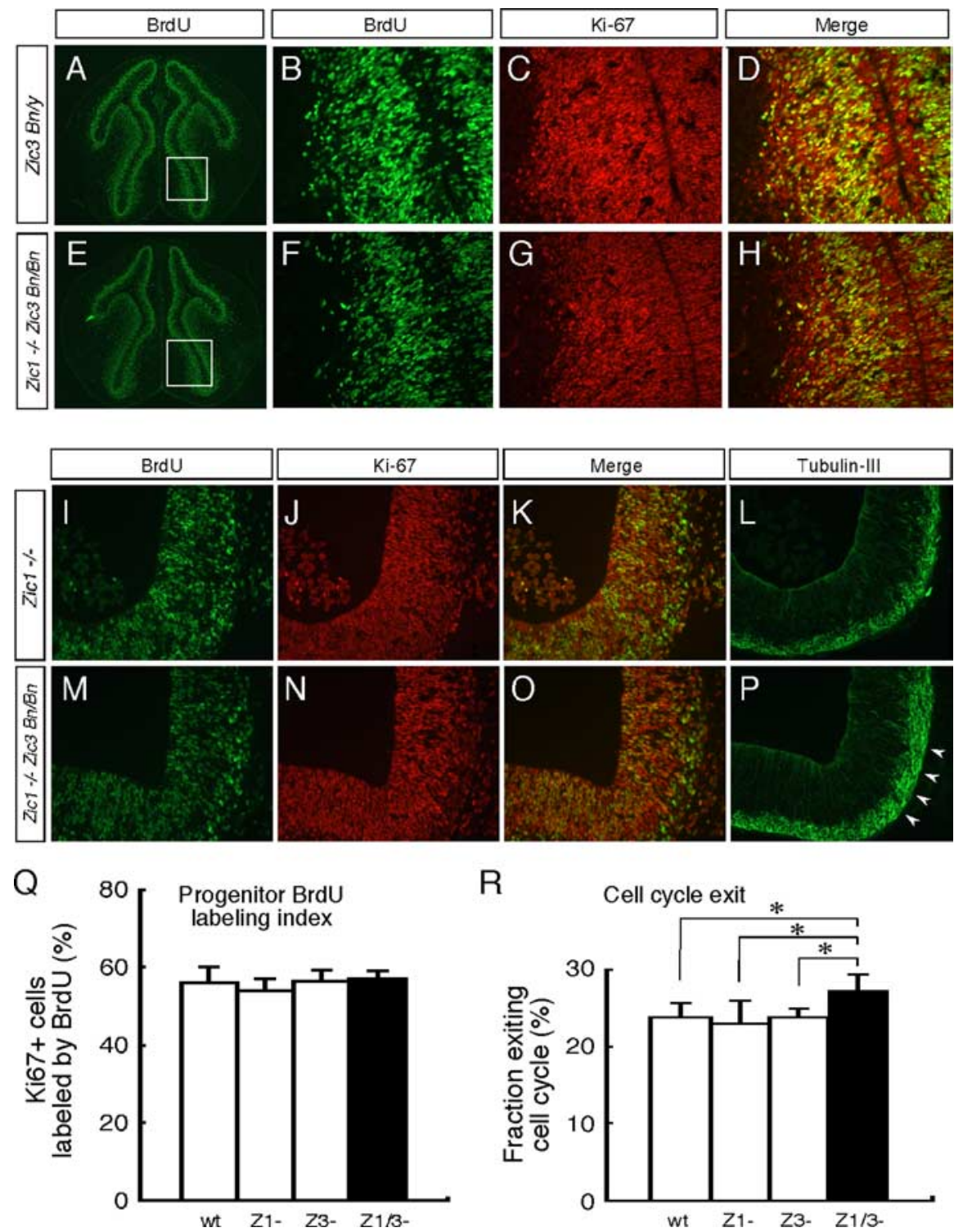

Figure 6. Proliferation and differentiation of neural progenitors in the Zic1/3 mutant. $\boldsymbol{A}-\boldsymbol{H}$, BrdU-labeling index analysis. Coronal sections through septum of Zic3 Bn/Y (A-D) and Zic1/3 (Zic1-/- Zic3 Bn/Bn) (E-H) E13.5 embryos after $1 \mathrm{~h}$ pulse labeling of BrdU are shown. Immunofluorescence staining for BrdU (green; $\boldsymbol{A}, \boldsymbol{B}, \boldsymbol{E}, \boldsymbol{F}$ ) and Ki67 (red; $\boldsymbol{C}, \boldsymbol{G}$ ) of the embryo is shown. $\boldsymbol{B}-\boldsymbol{D}$ and $\boldsymbol{F}-\boldsymbol{H}$ are higher magnifications of the areas indicated in $\boldsymbol{A}$ and $\boldsymbol{E}$, respectively. $\boldsymbol{D}$ and $\boldsymbol{H}$ are merged views of $\boldsymbol{B}$ and $\boldsymbol{C}$, and $\boldsymbol{F}$ and $\mathbf{G}$, respectively. The results were quantified and used to calculate the BrdU-labeling index in $\mathbf{Q}$. $\boldsymbol{I}-\boldsymbol{P}$, Cell cycle exit fraction analysis. Animals were exposed to a single-pulse label of BrdU at E11.5; $24 \mathrm{~h}$ later (atE12.5), the animals were killed and subjected to immunofluorescence staining for BrdU (green) and Ki67 (red). $\boldsymbol{K}$ and $\boldsymbol{O}$ are merged views of $\boldsymbol{I}$ and $\boldsymbol{J}$, and $\boldsymbol{M}$ and $\boldsymbol{N}$, respectively. The results were quantified and used to calculate cell fractions exiting the cell cycle $(\boldsymbol{R})$. Neighboring sections were stained with class-III $\beta$-tubulin $(\boldsymbol{L}, \boldsymbol{P})$, which showed a thicker layer in Zic1/3 than in Zic1-/- ( $\boldsymbol{P}$, arrowheads). Q, Quantification of progenitor BrdU-labeling index. The percentage of BrdU-labeled cells in Ki67-positive proliferating cells was not altered in Zic1-/-, Zic3 $\mathrm{Bn} / \mathrm{Y}$, or Zic1/3. Results represent mean numbers of BrdU-labeled cells as percentages of total numbers of Ki67-labeled cells. Error bars indicate SEMs. $R$, Quantification of cell fractions exiting cell cycle. The ratio of the number of cells labeled only with BrdU (BrdU+/Ki67 - , no longer dividing) to the number of double-labeled BrdU+/Ki67 + cells (yellow, re-entered cell cycle) was compared. Zic1/3 showed a significantly higher ratio than did the wild type, Zic1-/-, or Zic3 Bn/Y (or Bn/Bn). The results represent the mean ratios of the numbers of cells no longer dividing to the numbers of cells that had re-entered the cycle in the

of the mitral cell layer may be plausible if the comparable number of cells was packed into the limited perimeter of the small OB.

\section{Possible contribution of medial progenitors to $\mathrm{OB}$} interneurons in the embryonic telencephalon

The above analyses suggested that depletion of the neuronal progenitors for the $\mathrm{OB}$ interneurons is a main feature of the Zic1/Zic3 

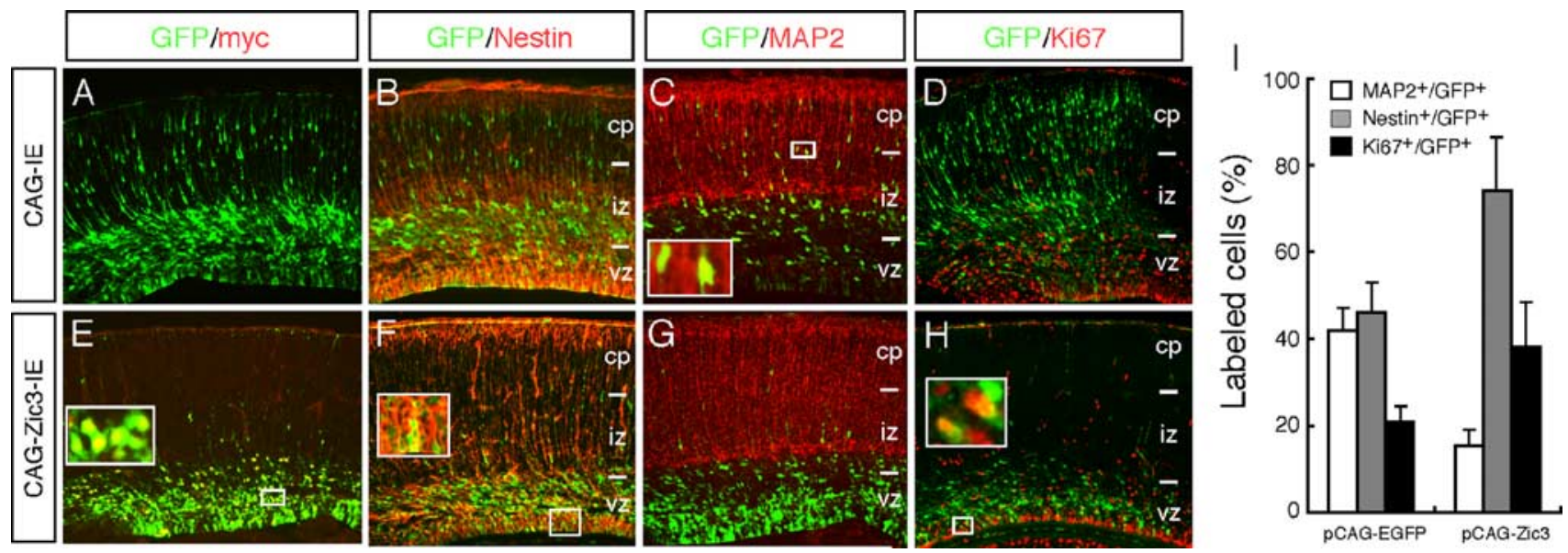

Figure 7. Misexpression of Zic3 inhibited neuronal differentiation in cerebral cortex. A-H, AZic3 expression plasmid vector, pCAG-myc-tagged-Zic3-IRES EGFP (CAG-Zic3-IE) (E-H) or its control vector, pCAG-IRES-EGFP (CAG-EGFP) $(\boldsymbol{A}-\boldsymbol{D})$ was transfected by in utero electroporation into the dorsolateral cerebral cortex, where Zic3 is not expressed. Electroporation was performed at E14.5, and the fates of the transfected cells were examined at E17.5 by examining the EGFP signals. Transfected cells were detected with immunofluorescence staining for anti-GFP ( $\boldsymbol{A}-\boldsymbol{H})$, anti-myc epitope $\operatorname{tag}(\boldsymbol{A}, \boldsymbol{E})$, the neural progenitor marker Nestin $(\boldsymbol{B}, \boldsymbol{F})$, neuronal marker MAP2 $(\boldsymbol{C}, \boldsymbol{G})$, and proliferation marker Ki67 $(\boldsymbol{D}, \boldsymbol{H})$. Whereas many CAG-EGFP-transfected cells (EGFP + ) migrated out of the VZ and were located in the intermediate zone (iz) and cortical plate (Cp) (A), CAG-Zic3-transfected cells (EGFP+) remained in the VZ (E). CAG-Zic3-transfected cells were generally negative for MAP2 production $(\boldsymbol{G})$, but produced Nestin (insets in $\boldsymbol{F}$ ). Nestin staining outside the VZ was also observed in the blood vessels. $\boldsymbol{I}$, Quantification of the percentage of MAP2-expressing neurons or Nestin-expressing precursor cells in the transfected (EGFP+) cells. The results represented in $\boldsymbol{A}-\boldsymbol{H}$ were examined as in Materials and Methods. The results are shown as the mean percentage of four independent experiments. Error bars indicate SDs.

OB abnormality. It is known that the OB interneuron progenitors migrate through a rostral migratory stream (RMS) from the telencephalic SVZ, whereas the OB projection neurons are supplied from a different source (Hinds, 1968a,b; Luskin, 1998). However, as far as we could determine from a literature search, there have been no clear results indicating the contribution of the medial telencephalon, which was severely defective in $\mathrm{Zic1/3}$, to the olfactory neurons through rostral migration. To test whether loss of the OB interneurons was attributable to a deficit in the septum, we performed a focal transfection of EGFP-expressing plasmid into the medial wall of the lateral vesicle by in utero electroporation (Fig. 9). As a control experiment, we electroporated the same plasmid into the lateral wall of the lateral ventricle (Fig. $9 \mathrm{~A}$, left brain). This control electroporation on E12.5 to E14.5 embryos labeled the neuronal progenitors that migrated and differentiated into OB interneurons at P4 (Fig. 9A) (data not shown). When we introduced the EGFP-expressing plasmid into the medial wall of the lateral ventricle, EGFP + cells were detected in the postnatal $\mathrm{OB}$ (Fig. 9A, right brain). We confirmed that EGFP+ cells were located only in the medial wall of the lateral ventricle (Fig. 9D,E) and in the RMS (Fig. 9E, arrowheads). Detailed examination of the medially electroporated brain showed that most of EGFP+ cells in $\mathrm{OB}$ were periglomerular interneurons (Fig. 9F, G) (the dendrites of which were typically arborized within the glomeruli) (Fig. 8G, dashed circles) in the glomerular layer, and some others were granule interneurons in the granule cell layer. The predominant labeling of periglomerular interneurons versus granule cell layer neurons was observed in 21 of 28 medially electroporated brains, whereas the laterally electroporated brains did not show such tendency (10 of 12) (Fig. 9A-C) (data not shown). Although this point may need verification by a more comprehensive tracing study, the current results suggest that medial telencephalic cells can migrate rostrally and differentiate into OB interneurons.

\section{Discussion}

Zic1 and Zic3 regulate neuronal progenitor proliferation and differentiation in the developing telencephalon

We investigated the involvement of Zicl and Zic3 in medial forebrain development by generating a $Z i c 1 / 3$ double mutant and misexpressing Zic3 in the developing cerebral cortex. Previously we observed an inhibitory effect of misexpressed Zic1 on neuronal differentiation in the chick spinal cord (Aruga et al., 2002a) and premature neuronal differentiation in $\mathrm{Zicl}-/-$ and $Z i c 1+/-Z i c 2 k d /+$ cerebella (Aruga et al., 2002b). These results suggest that $Z i c 1$ promotes the expansion of neuronal precursors by inhibiting neuronal differentiation. In the present study, we observed signs of premature differentiation in the Zic1/3 septum (i.e., enhanced exit from the cell cycle and an increase in the proportion of differentiated neurons) (Fig. 6) and an inhibitory effect of misexpressed Zic3 on cortical neuron differentiation. Together, these pieces of evidence support the idea that Zic1 and Zic3 have a common molecular function to expand the number of neuronal precursors by inhibiting the progression of neuronal differentiation during forebrain development. This idea is also consistent with the fact that Zic1 and Zic3 have similar DNAbinding properties and similarly activate reporter genes in cultured cells (Mizugishi et al., 2001).

Although this study focused on the cell-autonomous function of Zic1 and Zic3, developmental regulation through secretory factors should be taken into account, because the subtle downregulation of $D l \times 2$ in the LGE and thinning of the cerebral cortex may not be fully explained by these cell-autonomous functions. Secretory factors affected by the reduction in size of the choroid plexus, as well as those expressed in the cortical hem may be involved in the Zic1/3 forebrain abnormality. This point of view may be particularly important to consider the hippocampal defect in $Z i c 1 / 3$.

Developmentally, the rodent hippocampus arises at the caudomedial edge of the continuous dorsal telencephalic neuroepithelium adjacent to the telencephalic roof (Stanfield and Cowan, 1979, 1988; Bayer, 1980). The cortical hem produces many members of the bone morphogenetic protein and Wnt families of inductive signaling factors (Furuta et al., 1997; Grove et al., 1998), and is a candidate source of the signals regulating the induction and/or patterning of hippocampal development at the mediocaudal margin of the cerebral cortical neuroepithelium (Lee et al., 2000). Expression of Zic genes marks the dorsal margin of the 
neuroepithelium and dentate gyrus, and Zic3 is specifically expressed in the cortical hem and its derivatives. The hippocampal phenotype of the Zicl/3 mutant (hypoplastic hippocampal CA fields and dentate gyrus, and reduced size of fimbria) also supports the idea that Zic genes are crucial for hippocampal development. BrdUlabeling experiments (supplemental Fig. 4, available at www.jneurosci.org as supplemental material) suggested that cell proliferation is reduced in the hippocampal primordium as is the case in the cerebellum (Aruga et al., 1998, 2004) and septum (described below). Considering the presence of the Zic proteins in the hypoplastic region (supplemental Figs. 1, 4, available at www.jneurosci.org as supplemental material), the hippocampal phenotype is partly attributable to the loss of cell autonomous function of $\mathrm{Zic} 1$ and $\mathrm{Zic} 3$ proteins. However, it is possible that some Wnt-signaling abnormalities underlie the hippocampal phenotypes of the Zicl/3 mutants, because the Wnt3a-expressing hem is reduced in the mutants. Interestingly, the Wnt3a mutant mouse also shows hypoplastic hippocampus partially similar to those of Zic mutants (Lee et al., 2000). A comprehensive analysis of the Wnt-signaling components would be beneficial to develop a better understanding of the role of Zic1 and Zic3 in the dorsal telencephalon.

\section{Zic family and}

\section{telencephalon development}

Nagai et al. (2000) demonstrated that reduced expression of Zic2 leads to HPE, a medial forebrain anomaly in which the dorsal midline structure of the forebrain is missing or severely malformed. Although the forebrain phenotypes are more severe in $Z i c 2 ~ k d / k d$ than in the Zic1/3 mutant, the fact that the phenotype partly overlaps with that of $Z i c 1 / 3$ suggests functional similarity of the Zic1, Zic2, and Zic3 proteins in dorsal forebrain development. However, a hypoplastic septum and OB are not always obvious in Zic2 $k d / k d$ (Nagai et al., 2000). How can the phenotypic differences between Zic2 kd/kd and Zic1/3 mutants occur? One of the explanations would be the differences in the expression profiles of Zic1, Zic2, and Zic3. Zic2 expression in the prospective forebrain starts earlier than Zic1 and Zic3. During development from the streak to the somite stages, Zic2 expression is strong in the anterior ectoderm and mesoderm, and later in the medial forebrain, with weak expression in the OB. In contrast, Zic3 expression during development from the streak to somite stages is more posteriorly enhanced and is later strong in the hindbrain (Nagai
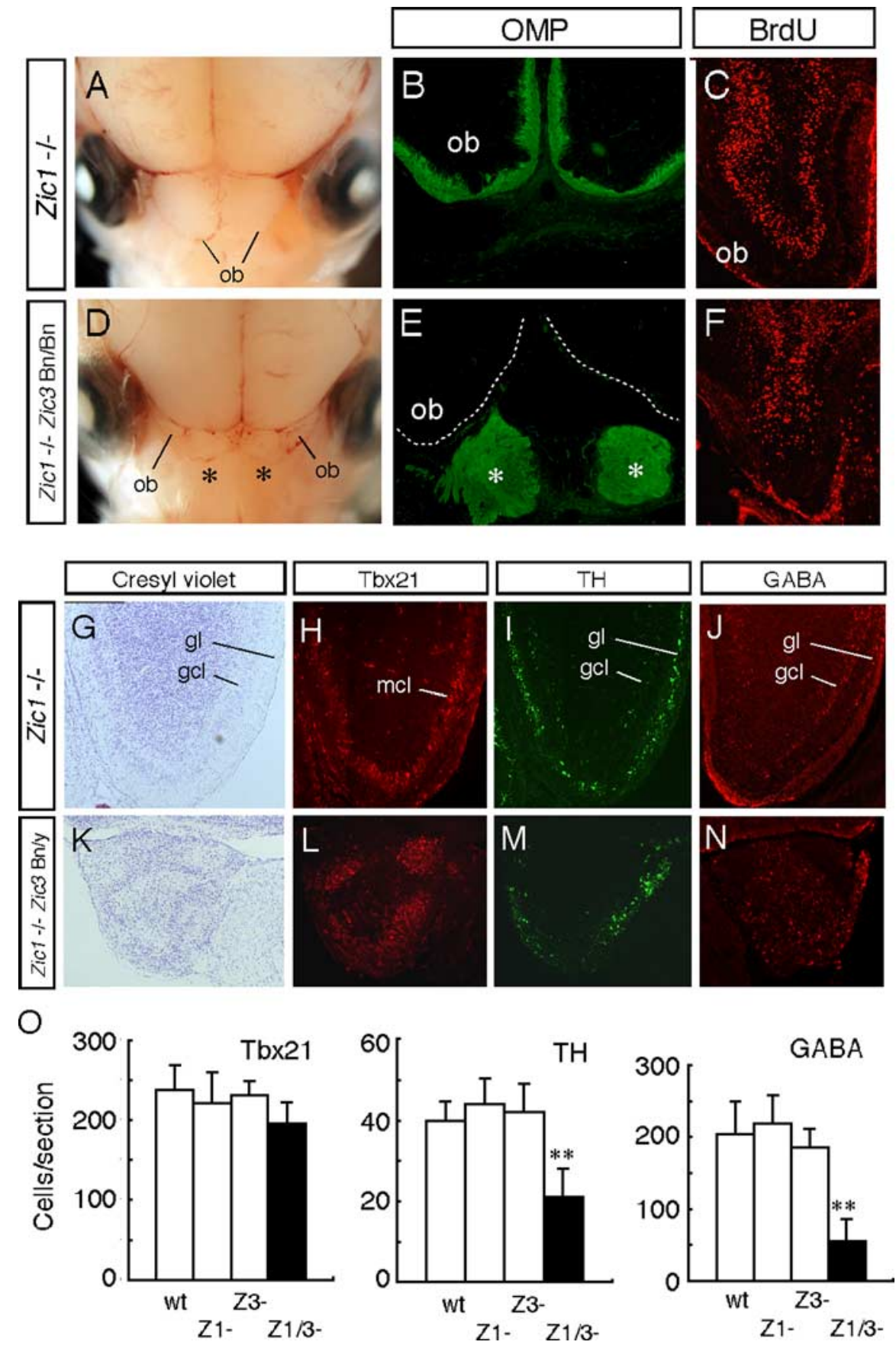

Figure 8. Defects in Zic1/3 OB. A, D, Dorsal views of the Zic1-/- $(\boldsymbol{A})$, and Zic1/3 (D) head at E18.5. In Zic1/3, unusual structures (asterisks) are seen in the interspace between the $\mathrm{OBS}$. $\boldsymbol{B}, \boldsymbol{E}$, Immunofluorescence staining for olfactory marker protein (OMP), which is located on the neuronal processes from the olfactory neurons, in Zic1-/- $(\boldsymbol{B})$ and Zic $1 / 3(\boldsymbol{E})$. In Zic 1-/-, the olfactory nerve layer surrounded the whole surface of the $\mathrm{OB}$. In contrast, in the Zic $1 / 3$ mutant, no apparent olfactory nerve layer was present and most of the olfactory axons terminated in fibrocellular mass-like structures (asterisks in $\boldsymbol{E}$ ). $\boldsymbol{C}, \boldsymbol{F}$, Immunofluorescence staining for BrdU atE15.5. The embryo was labeled with BrdU for $1 \mathrm{~h}$ before being killed. $\mathbf{G}-\mathbf{N}$, Neuronal subsets in Zic $1 / 30 B$. Cresyl violet staining $(\boldsymbol{G}, \boldsymbol{K})$ and immunofluorescence staining for $\operatorname{Tbx} 21(\boldsymbol{H}, \boldsymbol{L}), \operatorname{TH}(\boldsymbol{I}, \boldsymbol{M})$, and $G A B A(\boldsymbol{J}, \boldsymbol{N})$ in horizontal sections of E18.5 OBs of Zic1-/- $(\mathbf{G}-\boldsymbol{J})$ and Zic1/3 $(\boldsymbol{K}-\boldsymbol{N})$ are shown. $\mathbf{0}$, Quantification of OB neurons examined in sections. The number of neurons positive for Tbx21, $\mathrm{TH}$, and GABA in the $\mathrm{OB}$ were counted in each section. The mean numbers of immunoreactive cells in each $O B$ section, including the maximum diameter of the $O B$, were compared. Cells were counted in wild type $(n=6), Z i c 1-/-$ $(n=5)$, Zic3 Bn/Y or Zic3 Bn/Bn ( $n=5)$, and Zic1/3 (black bars; $n=4)$ OBs in comparable sections. Error bars indicate SDs. ${ }^{* *} p<$ 0.01 by $t$ test. $\mathrm{mcl}$, mitral cell layer; gl, glomerular layer; gcl, granule cell layer.

et al., 1997; Elms et al., 2004; Inoue et al., 2007) and the SVZ of the medial forebrain, with strong expression in the OB. Zicl expression occurs after the late somite stage and is enhanced in the hindbrain, medial forebrain, and OB. These differences may ex- 

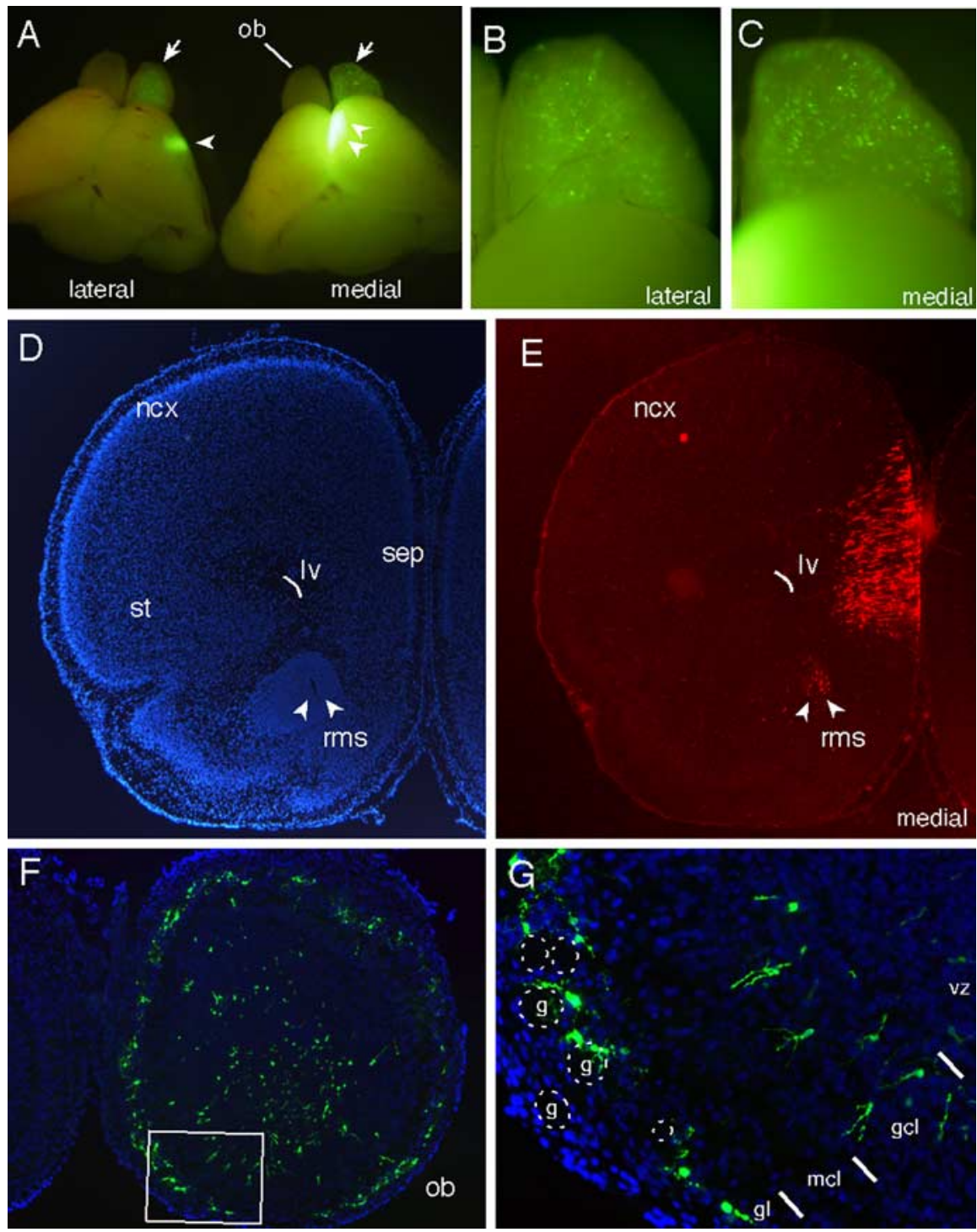

Figure 9. Focal transfection by in utero electroporation into the medial forebrain specifically targets $O B$ interneurons. $\boldsymbol{A}$, Electroporation of pCAG-EGFP into the lateral ganglionic eminence (left) and medial wall of the lateral ventricle (right) were performed at E13.5, and brains were fixed at P4. Dorsal views of the whole brains. Arrows, EGFP-labeled OB; arrowheads, the transfection sites. $\boldsymbol{B}, \boldsymbol{C}$, Higher magnification of the $\mathrm{OB}$ in $\boldsymbol{A}$. Control electroporation into the ganglionic eminences labeled the neuronal progenitors that migrated into the $\mathrm{OB}(\boldsymbol{B})$. Introduction of EGFP into the medial wall of the lateral ventricle also labeled the neuronal progenitors that migrated into the $O B(C) . D, E$, Coronal sections of the forebrain from a brain electroporated with pCAG-EGFP into the medial wall of the lateral ventricle were stained with stained with DAPI (blue, $\boldsymbol{D}$ ) or anti-GFP antibody (red, $\boldsymbol{E}$ ). EGFP was introduced into the septum, and clusters of EGFP + cells are seen in the ventral RMS (arrowheads, $\boldsymbol{D}, \boldsymbol{E}$ ). The transfected site was confirmed to be more caudally located. $\boldsymbol{F}, \mathbf{G}$, Coronal sections of the OB from the medially electroporated brain were stained with DAPI (blue) and anti-GFP antibody (green). A higher magnification of the region indicated in $\boldsymbol{F}$ is shown in $\boldsymbol{G}$, where the EGFP + cells have the typical shape of periglomerular interneurons (arborized within glomeruli; dashed circles) in the glomerular layer and granule interneurons in the granule cell layer. g, Glomeruli; gcl, granule cell layer; gl, glomerular layer; Iv, lateral ventricle; mcl, mitral cell layer; ncx, neocortex; st, striatum.

plain the absence of apparent forebrain phenotypes in the Zic1and Zic3-single mutants, and the OB phenotypes in the Zic2 mutant. Consistent with the expression profiles, the forebrain defects in $Z i c 2 \mathrm{kd} / \mathrm{kd}$ can be traced back to the early somite stage (E8.0) (T. Inoue and J. Aruga, unpublished observation). The forebrain defects in the Zic2 mutant may reflect an abnormality in the developmental process that is earlier than those in the Zic1 and Zic3 mutants, in which the abnormalities appear after E12.5. Even with these spatiotemporal differences, we may be able to conclude that Zic1, Zic2, and Zic3 together cooperatively control medial forebrain development.
Phylogenetically, both the telencephalon and $\mathrm{OB}$ were evolutionary innovations in the vertebrate ancestor. A recent molecular phylogenetic study suggested that Zic1, Zic2, and Zic3 belonged to the newly acquired subgroup of the Zic family gene in the vertebrate ancestor (Aruga et al., 2006). Considering their essential roles in telencephalon development, the appearance of Zic1, Zic2, and Zic3 may have had a role in establishing the basic structure of the vertebrate brain.

\section{Contribution of septal progenitors in OB development}

Most TF genes with essential roles in basal forebrain development (including proliferation, cell fate determination, and migration), such as Dlx1,Dlx2, Dlx5, Gsh1, Gsh2, Mash1, Nkx2.1, and Vax1, are expressed in both in the MGE and/or LGE and septum (Qiu et al., 1995; Anderson et al., 1997a, 2001; Sussel et al., 1999; Fode et al., 2000; Long et al., 2003; Taglialatela et al., 2004) (for review, see Marin and Rubenstein, 2001). Zic1, $Z i c 2$, and $Z i c 3$ are unique in that they are expressed only in the septum and not in the MGE or LGE. Therefore, we focused on the Zic1/3 septum to reveal the basis and consequence of its abnormalities. Although reduction in the number of cells is a commonly observed feature of Zic1, Zic2, Zic3, and Zic5 mutant CNSs (Aruga et al., 1998; Nagai et al., 2000; Purandare et al., 2002; Inoue et al., 2004), region-specific cell-type generation may also be affected by these mutations.

OB interneurons are classically thought to be generated by neural progenitors that migrate into the RMS from the SVZ of the ventral telencephalon (Bayer and Altman, 2004). In the embryonic forebrain, there appears to be at least three subcortical SVZs that are continuous with the OB: they are the SVZs of the septum, LGE, and MGE. Recently, on the basis of the patterns of expression of $D l \times 1, D l \times 2$, Dlx5, and GAD67, Long et al. (2003) suggested that there may be at least three distinct progenitor zones that contribute tangentially migrating precursors to OB local circuit neurons. They also pointed out the possibility that cells might migrate from the SVZ of the septum to the medial part of the OB. Although their suggestion showed foresight, it needed experimental evidence. Our analysis of the Zic1/3 OB was therefore interesting in that it tested their hypothesis, considering the localized expression and the hypoplastic phenotype in the septum. We observed poor development of the $\mathrm{OB}$ characterized by a strong reduction in the numbers of $\mathrm{OB}$ local circuit neurons whose progenitors were supplied from external origins. Together with our observations that medial progenitors electroporated with EGFP specifically 
differentiated into $\mathrm{OB}$ interneurons, these results suggest that the medial progenitors may contribute, at least in part, to OB interneurons in the embryonic telencephalon. Future studies will focus on establishing the properties of the medial progenitors, and how Zic genes regulate the migration and differentiation of the progenitors.

\section{References}

Anderson SA, Eisenstat DD, Shi L, Rubenstein JL (1997a) Interneuron migration from basal forebrain to neocortex: dependence on Dlx genes. Science 278:474-476.

Anderson SA, Qiu M, Bulfore A, Eisenstat DD, Meneses, Pederson S, Rubenstein JL (1997b) Mutations of the homeobox genes Dlx-1 and Dlx-2 disrupt the striatal subventricular zone and differentiation of late born striatal neurons. Neuron 19:27-37.

Anderson SA, Marin O, Horn C, Jennings K, Rubenstein JL (2001) Distinct cortical migrations from the medial and lateral ganglionic eminences. Development 128:353-363.

Aruga J (2004) The role of Zic genes in neural development. Mol Cell Neurosci 26:205-221.

Aruga J, Minowa O, Yaginuma H, Kuno J, Nagai T, Noda T, Mikoshiba K (1998) Mouse Zicl is involved in cerebellar development. J Neurosci 18:284-293.

Aruga J, Inoue T, Hoshino J, Mikoshiba K (2002a) Zic2 controls cerebellar development in cooperation with Zic1. J Neurosci 22:218-225.

Aruga J, Tohmonda T, Homma S, Mikoshiba K (2002b) Zicl promotes the expansion of dorsal neural progenitors in spinal cord by inhibiting neuronal differentiation. Dev Biol 244:329-341.

Aruga J, Ogura H, Shutoh F, Ogawa M, Franke B, Nagao S, Mikoshiba K (2004) Locomotor and oculomotor impairment associated with cerebellar dysgenesis in Zic3-deficient (Bent tail) mutant mice. Eur J Neurosci 20:2159-2167.

Aruga J, Kamiya A, Takahashi H, Fujimi TJ, Shimizu Y, Ohkawa K, Yazawa S, Umesono Y, Noguchi H, Shimizu T, Saitou N, Mikoshiba K., Sakaki Y, Agata K, Toyoda A (2006) A wide-range phylogenetic analysis of Zic proteins: implications for correlations between protein structure conservation and body plan complexity. Genomics 87:783-792.

Baker H, Liu N, Chun HS, Saino S, Berlin R, Volpe B, Son JH (2001) Phenotypic differentiation during migration of dopaminergic progenitor cells to the olfactory bulb. J Neurosci 21:8505-8513.

Bayer SA (1980) Development of the hippocampal region in the rat. I. Neurogenesis examined with $3 \mathrm{H}$-thymidine autoradiography. J Comp Neurol $190: 87-114$

Bayer SA, Altman J (2004) Development of the telencephalon: neural stem cells, neurogenesis, and neuronal migration. In: The rat nervous system (Paxinos G, ed), pp 27-75. San Diego: Academic.

Behar T, Ma W, Hudson L, Barker JL (1994) Analysis of the anatomical distribution of GAD67 mRNA encoding truncated glutamic acid decarboxylase proteins in the embryonic rat brain. Brain Res Dev Brain Res 77:77-87.

Brown SA, Warburton D, Brown LY, Yu CY, Roeder ER, Stengel-Rutkowski S, Hennekam RC, Muenke M (1998) Holoprosencephaly due to mutations in ZIC2, a homologue of Drosophila odd-paired. Nat Genet $20: 180-183$

Burgoyne RD, Cambray-Deakin MA, Lewis SA, Sarkar S, Cowan NJ (1988) Differential distribution of beta-tubulin isotypes in cerebellum. EMBO J 7:2311-2319.

Carrel T, Purandare SM, Harrison W, Elder F, Fox T, Casey B, Herman GE (2000) The X-linked mouse mutation Bent tail is associated with a deletion of the Zic3 locus. Hum Mol Genet 9:1937-1942.

Casarosa S, Fode C, Guillemot F (1999) Mash1regulates neurogenesis in the ventral telencephalon. Development 126:525-534.

Chenn A, Walsh CA (2002) Regulation of cerebral cortical size by control of cell cycle exit in neural precursors. Science 297:365-369.

Depaepe V, Suarez-Gonzalez N, Dufour A, Passante L, Gorski JA, Jones KR, Ledent C, Vanderhaeghen P (2005) Ephrin signalling control brain size by regulating apoptosis of neural progenitors. Nature 435:1244-1250.

DiSalvo CV, Zhang D, Jacobberger JW (1995) Regulation of NIH-3T3 cell G1 phase transit by serum during exponential growth. Cell Prolif 28:511-524.

Dwyer ND, O'Leary DD (2001) Tbrl conducts the orchestration of early cortical development. Neuron 29:309-311.
Eisenstat DD, Liu JK, Mione M, Zhong W, Yu G, Anderson SA, Ghattas J, Puelles L, Rubenstein JL (1999) DLX-1, DLX-2, and DLX-5 expression define distinct stages of basal forebrain differentiation. J Comp Neurol 414:217-237.

Elms P, Scurry A, Davies J, Willoughby C, Hacker T, Bogani D, Arkell R (2004) Overlapping and distinct expression domains of Zic2 and Zic3 during mouse gastrulation. Gene Expr Patterns 4:505-511.

Faedo A, Ficara F, Ghiani M, Aiuti A, Rubenstein JL, Bulfore A (2002) Developmental expression of the T-box transcription factor T-bet/Tbx21 during mouse embryogenesis. Mech Dev 116:157-160.

Fode C, Ma Q, Casarosa S, Ang SL, Anderson DJ, Guillemot F (2000) A role for neural determination genes in specifying the dorsoventral identity of telencephalic neurons. Genes Dev 14:67-80.

Franke B, Klootwijk R, Hekking JW, de Boer RT, ten Donkelaar HJ, Mariman EC, van Straaten HW (2003) Analysis of embryonic phenotype of Bent tail, a mouse model for X-linked neural tube defects. Anat Embryol 207:255-262.

Furuta Y, Piston DW, Hogan BL (1997) Bone morphogenetic proteins (BMPs) as regulators of dorsal forebrain development. Development 124:2203-2212.

Garber ED (1952) "Bent tail," a dominant, sex-linked mutation in the mouse. Proc Natl Acad Sci USA 38:876-879.

Grinberg I, Millen KJ (2005) The ZIC gene family in development and disease. Clin Genet 67:290-296.

Grinberg I, Northrup H, Ardinger H, Prasad C, Dobyns WB, Millen KJ (2004) Heterozygous deletion of the linked genes ZIC1 and ZIC4 is involved in Dandy-Walker malformation. Nat Genet 36:1053-1055.

Grove EA, Tole S, Limon J, Yip L, Ragsdale CW (1998) The hem of the embryonic cerebral cortex is defined by the expression of multiple Wnt genes and is compromised in Gli3-deficient mice. Development 124:2315-2325.

Guillemot F (2005) Cellular and molecular control of neurogenesis in the mammalian telencephalon. Curr Opin Cell Biol 17:639-647.

Hinds JW (1968a) Autoradiographic study of histogenesis in the mouse olfactory bulb. I. Time of origin of neurons and neuroglia. J Comp Neurol 134:287-304.

Hinds JW (1968b) Autoradiographic study of histogenesis in the mouse olfactory bulb. II. Cell proliferation and migration. J Comp Neurol 134:305-322.

Hinds JW (1972a) Early neuron differentiation in the mouse olfactory bulb. I. Light microscopy. J Comp Neurol 146:233-252.

Hinds JW (1972b) Early neuron differentiation in the mouse olfactory bulb. I. Electron microscopy. J Comp Neurol 146:253-276.

Inoue T, Hatayama M, Tohmonda T, Itohara S, Aruga J, Mikoshiba K (2004) Mouse Zic5 deficiency results in neural tube defects and hypoplasia of cephalic neural crest derivatives. Dev Biol 270:146-162.

Inoue T, Ota M, Mikoshiba K, Aruga J (2007) Zic2 and Zic3 synergistically control neurulation and segmentation of paraxial mesoderm in mouse embryo. Dev Biol, in press.

Klootwijk R, Franke B, van der Zee CE, de Boer RT, Wilms W, Hol FA, Mariman EC (2000) A deletion encompassing Zic3 in bent tail, a mouse model for X-linked neural tube defects. Hum Mol Genet 9:1615-1622.

Kosaka K, Aika Y, Toida K, Heizmann CW, Hunziker W, Jacobowitz DM, Nagatsu I, Streit P, Visser TJ, Kosaka T (1995) Chemically defined neuron groups and their subpopulations in the glomerular layer of the rat main olfactory bulb. Neurosci Res 23:73-88.

Lee SM, Tole S, Grove E, McMahon AP (2000) A local Wnt-3a signal is required for development of the mammalian hippocampus. Development 127:457-467.

Long JE, Garel S, Depew MJ, Tobet S, Rubenstein JLR (2003) DLX5 regulates development of peripheral and central components of the olfactory system. J Neurosci 23:568-578.

Luskin MB (1998) Neuroblasts of the postnatal mammalian forebrain: their phenotype and fate. J Neurobiol 36:221-233.

Marin O, Rubenstein JL (2001) A long remarkable journey: tangential migration in the telencephalon. Nat Rev Neurosci 2:780-790.

Mizugishi K, Aruga J, Nakata K, Mikoshiba K (2001) Molecular properties of Zic proteins as transcriptional regulators and their relationship to GLI proteins. J Biol Chem 276:2180-2188.

Nagai T, Aruga J, Takada S, Gunther T, Sporle R, Schughart K, Mikoshiba K (1997) The expression of the mouse Zic1, Zic2, and Zic3 gene suggests an 
essential role for Zic genes in body pattern formation. Dev Biol 182:299-313.

Nagai T, Aruga J, Minowa O, Sugimoto T, Ohno Y, Noda T, Mikoshiba K (2000) Zic2 regulates the kinetics of neurulation. Proc Natl Acad Sci USA 97:1618-1623.

Nakahira E, Kagawa T, Shimizu T, Goulding MD, Ikenaka K (2006) Direct evidence that ventral forebrain cells migrate to the cortex and contribute to the generation of cortical myelinating oligodendrocytes. Dev Biol 291:123-131.

Nguyen Ba-Charvet KT, Brose K, Marillat V, Kidd T, Goodman CS, TessierLavigne M, Sotelo C, Chedotal A (1999) Slit2-mediated chemorepulsion and collapse of developing forebrain axons. Neuron 22:463-473.

Nieto M, Schuurmans C, Britz O, Guillemot F (2001) Neural bHLH genes control the neuronal versus glial fate decision in cortical progenitors. Neuron 29:401-413.

Niwa H, Ymamura K, Miyazaki J (1991) Efficient selection for highexpression transfectants. Gene 108:193-199.

Ohtsuka T, Ishibashi M, Gradwohl G, Nakanishi S, Guillemot F, Kageyama R (1999) Hes1 and Hes5 as Notch effectors in mammalian neuronal differentiation. EMBO J 18:2196-2207.

Ohtsuka T, Sakamoto M, Guillemot F, Kageyama R (2001) Roles of basic helix-loop-helix genes Hes1 and Hes5 in expression of neural stem cells of the developing brain. J Biol Chem 276:30467-30474.

Purandare SM, Ware SM, Kwan KM, Gebbia M, Bassi MT, Deng JM, Vogel H, Behringer RR, Belmont JW, Casey B (2002) A complex syndrome of left-right axis, central nervous system and axial skeleton defects in Zic3 mutant mice. Development 129:2293-2302.

Qiu M, Bulfone A, Martinez S, Meneses JJ, Shimamura K, Pedersen RA, Rubenstein JL (1995) Null mutation of Dlx-2 results in abnormal morphogenesis of proximal first and second branchial arch derivatives and abnormal differentiation in the forebrain. Genes Dev 9:2523-2538.

Rubenstein JL, Shimamura K, Martinez S, Puelles L (1998) Regionalization of the prosencephalic neural plate. Annu Rev Neurosci 21:445-477.

Saito T, Nakatsuji N (2001) Efficient gene transfer into the embryonic mouse brain using in vivo electroporation. Dev Biol 240:237-246.

Soria JM, Taglialatela P, Gil-Perotin S, Galli R, Gritti A, Verdugo JM, Bertuzzi
S (2004) Defective postnatal neurogenesis and disorganization of the rostral migratory stream in absence of the Vax1 homeobox gene. J Neurosci 24:11171-11181.

Stanfield BB, Cowan WM (1979) The development of the hippocampus and dentate gyrus in normal and reeler mice. J Comp Neurol 185:423-460.

Stanfield BB, Cowan WM (1988) The development of the hippocampal region. Cereb Cortex 7:91-131.

Stenman J, Toresson H, Campbell K (2003) Identification of two distinct progenitor populations in the lateral ganglionic eminence: implications for striatal and olfactory bulb neurogenesis. J Neurosci 23:167-174.

St. John JA, Clarris HJ, McKeown S, Royal S, Key B (2003) Sorting and convergence of primary axons are independent of the olfactory bulb. J Comp Neurol 464:131-140.

Sussel L, Marin O, Kimura S, Rubenstein JL (1999) Loss of Nkx2.1 homeobox gene function results in a ventral to dorsal molecular respecification within the basal telencephalon: evidence for a transformation of the pallium into the striatum. Development 126:3359-3370.

Taglialatela P, Soria JM, Caironi V, Moiana A, Bertuzzi S (2004) Compromised generation of GABAergic interneurons in the brains of Vax1-/mice. Development 131:4239-4249.

Takada S, Stark KL, Shea MJ, Vassileva G, McMahon JA, McMahon AP (1994) Wnt-3a regulates somite and tailbud formation in the mouse embryo. Genes Dev 8:174-189.

Toida K, Kosaka K, Aika Y, Kosaka T (2000) Chemically defined neuron groups and their subpopulations in the glomerular layer of the rat main olfactory bulb-IV. Intraglomerular synapses of tyrosine hydroxylaseimmunoreactive neurons. Neuroscience 101:11-17.

Turner DL, Weintraub H (1994) Expression of achaete-scute homolog 3 in Xenopus embryos converts ectodermal cells to neural fate. Genes Dev 15:1434-1447.

Yoshihara S, Omichi K, Yanazawa K, Kitamura K, Yoshihara Y (2005) Arx homeobox gene is essential for development of mouse olfactory system. Development 132:751-762.

Zaki PA, Quinn JC, Price DJ (2003) Mouse models of telencephalic development. Curr Opin Genet Dev 13:423-437. 